\title{
Contractual Resolutions of Financial Distress
}

\author{
Nicola Gennaioli and Stefano Rossi* \\ CREI Universitat Pompeu Fabra, CEPR and Purdue, CEPR, ECGI
}

This version: May 2012

\begin{abstract}
In a financial contracting model, we study the optimal debt structure to resolve financial distress. We show that a debt structure where two distinct debt classes co-exist - one class fully concentrated and with control rights upon default, the other dispersed and without control rights - removes the controlling creditor's liquidation bias when investor protection is strong. These results rationalize the use and the performance of floating charge financing, debt financing where the controlling creditor takes the entire business as collateral, in countries with strong investor protection. Our theory predicts that the efficiency of contractual resolutions of financial distress should increase with investor protection.
\end{abstract}

JEL classification: G33, K22.

Keywords: Financial Distress, Investor Protection, Financial Contracting.

\footnotetext{
${ }^{*}$ CREI, Universitat Pompeu Fabra, and CEPR E-mail: ngennaioli@crei.cat; and Purdue, CEPR, and ECGI, Email: rossis@purdue.edu. We thank Viral Acharya, Philippe Aghion, Ken Ayotte, Mike Burkart, Hülya Eraslan, Julian Franks, Mariassunta Giannetti, Oliver Hart, Giacomo Ponzetto, Andrei Shleifer, Ernst-Ludwig von Thadden, Katrin Tinn, Lucy White, Yanos Zylberberg as well as participants at the Western Finance Association 2010 Meetings in Victoria, the Financial Intermediation Research Society 2010 Meetings in Florence, the NBER Corporate Finance Meetings, Arizona State University, Bocconi University, Duke University, Harvard Business School, Harvard University, HEC Lausanne, HEC Paris, Helsinki School of Economics, Imperial College, London Business School, London School of Economics, Michigan State University, Norwegian School of Economics at Bergen, Stockholm School of Economics, the Swiss Finance Institute, the Wharton School at the University of Pennsylvania, at the Conference on Corporate Governance in Family/Unlisted Firms at University of Bern, and at the CEPR Conference on Financial Contracting: Theory and Evidence at University of Mannheim for helpful comments. Nicola Gennaioli also thanks the support of the Barcelona Economics Program of CREA. Samuel Lee provided excellent research assistance.
} 


\section{Introduction}

Existing theoretical work on bankruptcy has focused on the functioning of state provided reorganization or liquidation procedures. However, recent empirical studies document that in many countries firms resolve financial distress privately, by using debt contracts. Upon non-repayment, these contracts allocate control rights over the decision whether to reorganize or liquidate the firm to a large creditor [Franks and Sussman (2005a)]. The use of these contractual resolutions of financial distress correlates positively with measures of ex post efficiency, such as the likelihood of efficient reorganization and creditors' recovery rates, as well as ex ante efficiency, such as credit market development [Djankov, Hart, McLiesh and Shleifer (2008)].

These findings raise two challenges for the literature on financial contracting. First, such literature associates creditor control with a bias towards liquidation. Such bias may counter strategic default, boosting ex ante financing, or simply reflect creditors' lack of interest in reorganization [see Hart (1995)]. Either way, by linking creditor control to pervasive liquidation, conventional theories do not explain the frequent use of creditor control in the real world and the fact that it often leads to the reorganization of viable firms. Second, existing analyses of debt structure either focus on a single-creditor setting [e.g. Aghion and Bolton (1991), Hart and Moore (1998)], or, in the case of multiple creditors, they do not study the allocation of control rights over the liquidation decision [e.g. Bolton and Scharfstein (1996), Diamond (2004)]. As such, these theories do not rationalize the allocation of the reorganization v. liquidation decisions across the different classes of creditors that we observe in the real world. ${ }^{1}$

In this paper, we address these issues by: i) studying theoretically the optimal debt structure to resolve financial distress, and ii) outlining under which conditions such debt structure yields an efficient resolution of financial distress. As in Aghion and Bolton (1992), we allow debt contracts to allocate control rights over the reorganization v. liquidation decision. As in Hart and Moore (1998), we assume that cash flows are less pledgeable than liquidation proceeds. We allow the pledgeability of cash flows to vary and interpret it as a proxy for investor protection, which has been shown to shape international financing patterns [e.g. La Porta et al. (1998)]. This focus on investor protection allows us to obtain testable predictions on how the efficiency of contractual resolutions of financial distress should vary across countries.

\footnotetext{
${ }^{1}$ Dewatripont and Tirole (1994) rationalize the mix of equity and debt, Berglöf and von Thadden (1994) the mix of short and long term debt, and Winton (1995) the mix of secured and unsecured claims. None of the above, however, rationalizes the heterogeneity of creditors in terms of their control over the liquidation v. reorganization decision.
} 
We find that the optimal debt structure consists of two classes of creditors. One class is concentrated on a large creditor who has exclusive control over the liquidation v. reorganization decisions. This creditor is given both physical collateral and an equity stake in the reorganized firm. Crucially, his claim is under-collateralized, in the sense that it pledges a share of physical assets that is smaller than the creditor's equity stake. The other debt class is dispersed among small creditors who have no control rights. These creditors are entitled to obtain some liquidation proceeds, but are "wiped out" in reorganization.

The logic of this debt structure is insightful. Giving the large creditor equity in the reorganized firm is necessary to remove his liquidation bias. However, since liquidation proceeds are easier to pledge than reorganization cash flows, under-collateralization is also required to induce him to fully internalize the upside of reorganization. Under-collateralization, which is a novel feature of our analysis, works best in the presence of a second debt class: distributing the remaining liquidation proceeds to a debt class without control rights, as opposed to "leaving them on the table", allows to maximize total repayment to all creditors. The debt class of non-controlling creditors should then be dispersed. Dispersion here is useful to prevent collusion among non-controlling creditors, which would reintroduce a liquidation bias. This notion differs from the traditional idea that debt dispersion makes lenders tough following a strategic default [e.g. Bolton and Scharfstein (1996), Diamond (2004)]. The presence of two debt classes differing in their control rights can also rationalize the coexistence of "bank" and "arm's length" debt in a firm's debt structure.

Interestingly, our optimal debt structure captures the salient features of floating charge financing, which is a common way to resolve financial distress by contract in the U.K. and other common law countries [Franks and Sussman (2005a)]. In its basic version a large creditor, typically a bank, lends under both a "fixed charge" (i.e. physical collateral), and a "floating charge", which is a collateral to the whole reorganized firm, including working capital, intangibles and future cash flows. As such, the floating charge effectively gives the creditor in control an "equity-like" stake in the reorganized firm. Upon default, the creditor holding the floating charge has the exclusive right to reorganize or liquidate the firm. The rest of the lending is dispersed among secured and unsecured claims. Our main contribution is thus to rationalize these key features of floating charge financing.

We find that the performance of creditor control is shaped by investor protection. When investor protection is strong, contracts can pledge the controlling creditor a large share of the firm's reorganization value, so that any liquidation bias is removed and the first best is attained. When investor protection is low, committing to ex post liquidation is the only way for the debtor to ensure 
break even ex ante. As a result, our flexible debt structure works best in developed countries, where investors are more protected, consistent with extant evidence on financial contracting [Lerner and Schoar (2005), Bergman and Nikolaievski (2007), Qian and Strahan (2007)].

It is important to stress that ours is a positive analysis. We neither aim to compare the efficiency of contractual v. state mandated bankruptcy nor to claim that ex ante debt structures and creditor control are the only efficient way to resolve financial distress. Indeed, our theory does not consider the effects of liquidation on third parties, e.g., workers or tort creditors, which is a main justification for formal bankruptcy procedures [e.g. Bolton and Rosenthal (2002); Biais and Mariotti (2008)]. On the other hand, our optimal contracting framework can inform the normative literature on bankruptcy by identifying some of the properties of optimal bankruptcy mechanisms. A handful of recent papers study bankruptcy design from an optimal contracting perspective [Ayotte and Yun (2009), Bisin and Rampini (2006), Berkovitch and Israel (1999), Berglöf et al. (2010)] but they do not study the allocation of control rights over the reorganization v. liquidation decision. As we discuss in Section 6, our analysis provides a foundation for the bankruptcy procedure proposed by Aghion, Hart and Moore (1992, AHM henceforth) and for the cash auction mechanism proposed by Baird (1986) and Jensen (1989), but we also show that our two-tier debt structure works better than either the AHM proposal or cash auctions if investor protection is not very strong.

The paper proceeds as follows. Section 2 presents the basic model. Section 3 studies the case with one creditor. Section 4 studies the case with multiple creditors and presents the central results of the paper about the allocation of control among multiple creditors. Section 5 discusses the connection of our results with real-world resolutions of financial distress. Section 6 concludes. The Appendix contains proofs and extensions.

\section{The Model}

We describe the basic setup in Section 2.1 and the contracting frictions in Section 2.2.

\subsection{The Basic Setup}

There are three dates, $t=0,1,2$. At $t=0$ a penniless entrepreneur, $E$, seeks funding to set up the physical assets of a firm at a cost $K>0$. We first consider the case of one investor, $I$, who has money but no human capital to run the firm. In Section 4 we obtain our main results in the case with multiple creditors. Under $E$ 's management the firm generates cash flow $y_{t}(\omega)$ at $t=1,2$, 
where $\omega \in \Omega$ is the state of nature, realized at $t=1$. There are three possible states, $\Omega \equiv\{G, U, B\}$. Figure 1 reports the firm's cash flows in different periods and states.

Figure 1. States of Nature

\begin{tabular}{cccc}
\hline \hline$\omega$ & $\operatorname{Pr}(\omega)$ & $y_{1}(\omega)$ & $y_{2}(\omega)$ \\
\hline$G$ & $\pi$ & $\bar{y}_{1}$ & $\bar{y}_{2}$ \\
$U$ & $(1-\pi) / 2$ & 0 & $\bar{y}_{2}$ \\
$B$ & $(1-\pi) / 2$ & 0 & $\underline{y}_{2}$ \\
\hline \hline
\end{tabular}

With probability $\pi$ the state is $\omega=G$. In this case, performance is "good" in both the interim date $t=1$ and the final date $t=2$ : the cash flows are $y_{1}(G)=\bar{y}_{1}>0$ and $y_{2}(G)=\bar{y}_{2}>0$. With probability $(1-\pi) / 2$ the state is $\omega=U$. In this case, the firm "underperforms" in the interim date, before recovering to good performance in the final date: cash flows are $y_{1}(U)=0$ and $y_{2}(U)=\bar{y}_{2}$. With probability $(1-\pi) / 2$ the state is $\omega=B$. In this case, performance is "bad" in both dates: cash flows are $y_{1}(B)=0$ and $y_{2}(B)=\underline{y}_{2}$, where $\underline{y}_{2}<\bar{y}_{2}$. In states $U$ and $B$ where the interim cash flow is zero, we refer to the firm as being in "financial distress". The cash flow at $t=2$ is higher in $U$ than in $B$, so that one can think of $B$ as a state of "economic distress".

At the end of $t=1$ and before $t=2$ the physical assets of the firm can be liquidated, yielding $L$. One can think of $L$ as representing the value of the firm in a piecemeal liquidation or under the management of the investor $I$, as opposed to the value $y_{2}(\omega)$ generated by a reorganization. The reorganization value $y_{2}(\omega)$ can be interpreted as the value of the firm under $E$ 's management or under an alternative management team with the same managerial skills/human capital as $E$.

With respect to the information structure, we assume that parties have symmetric information throughout. In particular, nobody knows the state $\omega$ at $t=0$, and both $E$ and $I$ perfectly learn $\omega$ - and thus the firm's reorganization value - at $t=1$.

We make the following two parametric assumptions:

A.1: $\bar{y}_{1}>\bar{y}_{2}>L>\underline{y}_{2}>0$,

A.2: $\pi \bar{y}_{2}+L>K$

Besides imposing $\bar{y}_{1}>\bar{y}_{2}$ (which only simplifies the exposition), A.1 implies that output is maximized by liquidating the firm's assets if and only if $\omega=B$. A.2 instead ensures that the liquidation value $L$ is sufficiently large that automatic liquidation often ensures break even. As we will discuss in Section 3.5, also A.2 only simplifies the exposition. This setup helps us illustrate 
our findings in the most intuitive manner. Appendix A2.1 shows formally that our basic results generalize to a setting where reorganization as well as liquidation values are stochastic and take on a continuum of values. ${ }^{2}$

\subsection{Contracting Frictions}

Parties write an optimal contract subject to two frictions. The first, crucial, friction captures the extent of legal protection of investors against managerial tunneling. This is measured by the share $\alpha \in[0,1]$ of the firm's cash flows $y_{t}(\omega)$ that $E$ can be legally compelled to pay to $I$ ex post, and which therefore $E$ can credibly pledge to $I$ ex ante. The remaining share $(1-\alpha)$ of cash flows is retained by $E$, and as a result cannot be pledged to $I$. Legal protection against tunneling increases in $\alpha$. Our model nests the Hart and Moore (1998) case of unverifiable cash flows as a special case when $\alpha=0$. When $\alpha>0$ the cash flows are partially verifiable. One possible interpretation is that $(1-\alpha) \cdot y_{t}(\omega)$ are the non-dissipative private benefits generated under limited investor protection $\alpha$ [see e.g. Shleifer and Wolfenzon (2002)]. In the spirit of Hart and Moore (1998), physical collateral $L$ can be fully pledged to $I$. Our results go through even if physical assets can be only partially pledged to $I$, as long as they remain more pledgeable than cash flows.

Given these assumptions, at $t=1$ the entrepreneur can be compelled to pay to $I$ at most $L+\alpha y_{1}(\omega)$, namely the value of physical assets $L$ plus the amount $\alpha y_{1}(\omega)$ of first period cash flows that $E$ is unable to divert. At $t=2$ the entrepreneur can be compelled to pay to $I$ up to $\alpha y_{2}(\omega)$. The latter feature implies that when $\alpha>0$ there is a potential incentive for $I$ to reorganize, unlike in models where cash flows are fully non-verifiable and $\alpha=0$.

The second contracting friction in our model is that courts cannot verify the realization of $\omega$. Courts can only observe the realization of cash flows ex post, which is an imperfect signal of $\omega$. In particular, following a realization of first period cash flows $y_{1}(\omega)=0$, courts cannot distinguish between states $U$ and $B$. As a result, a contract mandating reorganization if the state is $U$ and liquidation if it is $B$ cannot be enforced by courts. This friction creates the scope for providing parties with the incentive to reveal their information about $\omega .^{3}$ On the other hand, courts perfectly verify whether the firm is reorganized or liquidated.

\footnotetext{
${ }^{2}$ We have formally proved that our results also extend to the case where at $t=1$ the entrepreneur has superior information about $y_{2}(\omega)$. The results are available upon request.

${ }^{3}$ In a previous version of the paper we formally proved that our main results (especially those under multiple creditors) are unchanged if we allowed the parties to contract on a noisy signal of $y_{2}(\omega)$. We interpreted the precision of the signal as an index of courts' ability to verify the firm's reorganization value. These results are available upon request. See Gennaioli (2011) for a formal model of court state verification and contracting.
} 
Figure 2 shows the timing of the model.

\section{Figure 2. Timeline}

$\begin{array}{lll}\text { Contracts written } & \text { Cash flows } \mathrm{y}_{1} \text { realized. } & \begin{array}{l}\text { Cash flows } \mathrm{y}_{2} \text { is } \\ \text { realized (if the firm } \\ \text { was not liquidated) }\end{array} \\ \text { Project undertaken } & I \text { and } E \text { learn state } \omega & \mathrm{t}\end{array}$

Party in control decides liquidation policy

Before describing the contract space, we introduce some notation. Variable $\rho \in\{0,1\}$ is an indicator taking value 1 if $E$ repays in full in state $G$ and 0 if he strategically defaults in the same state; $x^{c}$ is the allocation of control, defined as the probability that party $c \in\{E, I\}$ controls the liquidation/reorganization decision in $\omega \in\{U, B\}$; we allow liquidation to be probabilistic and denote by $\lambda^{c}(\omega) \in[0,1]$ the liquidation probability chosen by controlling party $c$ in $\omega \in\{U, B\}$. We consider contracts specifying:

i) the amount $D=K$ that $I$ lends to $E$;

ii) the probability $\lambda(\rho)$ of liquidation at $\rho$ in state $\omega=G$;

iii) the allocation of control $x^{E}, x^{I}$ where $x^{E}+x^{I}=1$;

iv) time-dependent repayments $d_{t}(\rho)$ for state $G$. In state $\omega \in\{U, B\}$, the contract specifies repayments $h_{L}^{c}$ and $h_{R}^{c}(\omega)$ that $I$ should receive in liquidation and reorganization, respectively, when party $c$ is in control.

Two remarks are in order. First, the indicator variable $\rho$ only captures default in $G$ and thus affects repayment only in such state. Indeed, in $\omega \in\{U, B\}$ there is no first period cash flow, and therefore strategic default does not arise, because $E$ has no funds in these states. This latter feature changes if $E$ borrows more than the investment cost (i.e., if $D>K$ ). For simplicity, in the remainder we focus on the case $D=K$, but after Proposition 1 we show that setting $D>K$ does not improve outcomes. 
Second, the repayment promised to the investor contingent on liquidation, $h_{L}^{c}$, can be a random variable. This implies that, at a certain allocation of control $c$, the party in control may find it profitable to take a different liquidation decision depending on the realization of $h_{L}^{c}$. As a result, the liquidation policy chosen by the party in control can be stochastic. In light of this possibility, when $c$ controls the firm in $\omega \in\{U, B\}$ liquidation occurs with average probability $\mathbb{E}\left[\lambda^{c}(\omega)\right]$, where the expectation is taken across different realizations of $h_{L}^{c}$. For most of the analysis the optimal $h_{L}^{c}$ is deterministic. A stochastic $h_{L}^{c}$ is only optimal in the cases analyzed in Section 3.4. To streamline notation, we denote the investor's expected first period repayment in state $\omega \in\{U, B\}$ by:

$$
d_{1}(\omega)=x^{I} \mathbb{E}\left[\lambda^{I}(\omega) h_{L}^{I}\right]+x^{E} \mathbb{E}\left[\lambda^{E}(\omega) h_{L}^{E}\right]
$$

Intuitively, in financial distress first period repayment is positive if and only if some assets are liquidated (i.e., $\lambda^{c}(\omega)>0$ for some $c$ ). Accordingly, we denote the expected second period repayment in state $\omega \in\{U, B\}$ by:

$$
d_{2}(\omega)=x^{I} h_{R}^{I}(\omega)\left\{1-\mathbb{E}\left[\lambda^{I}(\omega)\right]\right\}+x^{E} h_{R}^{E}(\omega)\left\{1-\mathbb{E}\left[\lambda^{E}(\omega)\right]\right\}
$$

which is positive if and only if liquidation is less than full (i.e., $\lambda^{c}(\omega)<1$ for some $c$ ).

Contractual repayments are subject to the feasibility constraints:

$$
d_{1}(0) \leq \alpha \bar{y}_{1}+\lambda(0) L ; \quad d_{2}(\rho) \leq \alpha \bar{y}_{2}[1-\lambda(\rho)] ; h_{R}^{c}(\omega) \leq \alpha y_{2}(\omega) ; h_{L}^{c} \leq L .
$$

Finally, the equilibrium first period repayment in $G, d_{1}(1)$, is determined by incentive compatibility and must satisfy $d_{1}(1) \leq \bar{y}_{1}$.

In the main analysis, we assume that there is full commitment, so that the contract signed at $t=0$ is always fulfilled ex post. After Proposition 1, though, we show that our main results carry to the case with limited commitment, in which renegotiation can occur according to a standard Nash-bargaining protocol. Note however that ex post renegotiation is not central to our analysis, because our main results arise under multiple creditors, when ex post renegotiation is impossible.

The contract space just described deserves a few comments. First, state $G$ can be fully contracted upon. This state can be identified by courts because its verifiable $t=1$ cash flow is $\alpha \cdot \bar{y}_{1}>0$, which differs from that of $\alpha \cdot 0=0$ occurring in $U$ and $B \cdot{ }^{4}$ Second, since courts cannot distinguish

\footnotetext{
${ }^{4} \mathrm{~A}$ convenient feature of our model is to focus on how the unverifiability of future reorganization cash flows affects
} 
states in $\omega \in\{U, B\}$, the liquidation proceeds $h_{L}^{c}$ promised to $I$ do not depend on $\omega$. Third, as in Aghion and Bolton (1992) the contract allocates the decision of whether to liquidate or reorganize to party $c=E, I$, who therefore chooses $\lambda^{c}(\omega)$. In particular, as in Aghion and Bolton (1992) we allow for the allocation of control $x^{c}$ to be a random variable. Fourth, second period repayments depend on the verifiable reorganization proceeds $\alpha \cdot y_{2}(\omega)$, allowing contracts to provide the controlling party with incentives to take an efficient decision. Our main restriction is to rule out the use of revelation games a' la Maskin (1999), which are however discussed in Section 3.5.

\section{The Case with One Creditor}

We now illustrate the optimality of under-collateralization and the effect of $\alpha$ on the resolution of financial distress, building intuition for the main case with multiple creditors in Section 4. The contract offered by $E$ to $I$ solves the program:

$$
\begin{aligned}
& \max _{\lambda(\rho), d_{t}(\rho), x^{E}, x^{I}, h_{R}^{I}(\omega), h_{R}^{E}(\omega), h_{L}^{I}, h_{L}^{E}} \pi\left\{\bar{y}_{1}+\lambda(1) L+[1-\lambda(1)] \bar{y}_{2}\right\}+ \\
& \frac{(1-\pi)}{2}\left\{\bar{y}_{2}-\left(\bar{y}_{2}-L\right) \cdot\left(x^{E} \mathbb{E}\left[\lambda^{E}(U)\right]+x^{I} \mathbb{E}\left[\lambda^{I}(U)\right]\right)\right\}+ \\
& \frac{(1-\pi)}{2}\left\{\underline{y}_{2}-\left(\underline{y}_{2}-L\right) \cdot\left(x^{E} \mathbb{E}\left[\lambda^{E}(B)\right]+x^{I} \mathbb{E}\left[\lambda^{I}(B)\right]\right)\right\} .
\end{aligned}
$$

Subject to the three constraints:

$$
\begin{gathered}
\pi\left[d_{1}(1)+d_{2}(1)\right]+\frac{(1-\pi)}{2}\left[d_{1}(U)+d_{1}(B)+d_{2}(U)+d_{2}(B)\right]=K, \\
\bar{y}_{1}+\lambda(1) L+[1-\lambda(1)] \bar{y}_{2}-d_{1}(1)-d_{2}(1) \geq \\
\bar{y}_{1}+\lambda(0) L+[1-\lambda(0)] \bar{y}_{2}-d_{1}(0)-d_{2}(0),
\end{gathered}
$$

optimal control allocation in financial distress. The alternative assumption that contract terms cannot be contingent on $\alpha y_{1}(\omega)$ would complicate the analysis but not affect our results. This statement is literally true if $y_{2}(\omega)$ can be generated under an alternative management team, as we formally show in Appendix A2.1. 


$$
\lambda^{c}(\omega)=\left\{\begin{array}{ll}
\arg \max _{\lambda \in[0,1]} \lambda\left(L-h_{L}^{E}\right)+(1-\lambda)\left[y_{2}(\omega)-h_{R}^{E}(\omega)\right] & \text { if } c=E \\
\arg \max _{\lambda \in[0,1]} \lambda h_{L}^{I}+(1-\lambda) h_{R}^{I}(\omega) & \text { if } c=I
\end{array} \text { for } \omega=U, B\right.
$$

Repayments must also satisfy the feasibility constraints described in Equation (4), the expressions for $d_{t}(\omega)$ in Equations (2) and (3), and $x^{E}+x^{I}=1$.

The objective function (5) is the total expected surplus created by the project under the equilibrium liquidation policy $\lambda(1)$. Equation (6) is the investor break-even constraint, which holds with equality because here we restrict to the case where the entrepreneur borrows exactly $K$.

There are then two incentive compatibility constraints. The first such constraint, captured by Equation (7), makes sure that in state $G$ the entrepreneur finds it profitable to repay in full at $t=1$, which justifies setting $\rho=1$ in the objective function and in the break-even constraint. The second incentive constraint, captured by Equation (8) makes sure that - conditional on the state being $\omega \in\{U, B\}$, on control being allocated to party $c$, and on a certain realization of $h_{L}^{c}$ (which we label $h_{L}^{c}$ with a slight abuse of notation) - the liquidation decision taken by the party in control maximizes his utility at $t=1$.

In Equation (5) the project's surplus is only a function of the equilibrium liquidation policy. Under assumption A.1 the first best policy is to deterministically reorganize the firm in $G$ and $U$ and to liquidate it in $B$. The problem, though, is that such policy cannot be written in the contract because courts cannot verify $\omega \in\{U, B\}$. In addition, attempts to implement such policy by inducing truthful revelation according to (8) may end up violating (6), thereby preventing $I$ from breaking even.

In light of these observations, we solve for the optimal contract as follows. First, we determine sufficient conditions under which parties can attain the first best by allocating control to the entrepreneur (E-control), or the investor (I-control), or both. After that, we consider which second best contract is optimal when neither E-control nor $I$-control allow parties to attain the first best. ${ }^{5}$

\footnotetext{
${ }^{5}$ By "first best" we mean a situation in which $E$ can finance the project and the reorganization decision is ex post efficient. First best could also be taken to mean a situation in which cash flows are fully contractible, namely $\alpha=1$. We follow Hart and Moore (1998) and Hart (1995) and adopt the former convention.
} 


\subsection{Optimal Contract in State $\omega=G$}

In state $G$ the contract maximizes investor repayment by discouraging strategic default by $E$. This is accomplished by using the following contract terms:

Lemma 1 In $G$, the optimal contract inefficiently liquidates the firm after strategic default, $\lambda(0)=$ 1 , and continues it otherwise, $\lambda(1)=0$. The entrepreneur can then commit to pay up to $d_{1}(1)=$ $\alpha \bar{y}_{1}+(1-\alpha) \bar{y}_{2}$ and $d_{2}(1)=\alpha \bar{y}_{2}$. Total repayment in state $G$ is therefore at most equal to:

$$
d_{1}(1)+d_{2}(1)=\alpha \bar{y}_{1}+\bar{y}_{2}
$$

Proof. To minimize E's payoff from strategic default, after $\rho=0$ the contract sets the highest possible payments $d_{1}(0)=\alpha \bar{y}_{1}+\lambda(0) L, d_{2}(0)=\alpha \bar{y}_{2}[1-\lambda(0)]$. By plugging these values in the incentive constraint we can rewrite $(7)$ as:

$$
d_{1}(1)+d_{2}(1) \leq \alpha\left(\bar{y}_{1}+\bar{y}_{2}\right)+\lambda(1)\left(L-\bar{y}_{2}\right)+\lambda(0)(1-\alpha) \bar{y}_{2},
$$

where the right hand side is maximized by setting $\lambda(1)=0, \lambda(0)=1$. As a result, in $G$ total repayment to $I$ is equal to (9). Since at $t=2$ repayment is at most $d_{2}(1)=\alpha \bar{y}_{2}$, the $t=1$ repayment is $d_{1}(1)=\alpha \bar{y}_{1}+(1-\alpha) \bar{y}_{2}$, which is feasible (i.e., less than $\bar{y}_{1}$ ) by A.1.

As in Hart and Moore (1998), strategic default is averted by inefficiently liquidating the firm upon non repayment. The firm is instead efficiently continued on the "full repayment" equilibrium path. Due to the threat of liquidation, at $t=1$ the entrepreneur is willing to pay up to his future control rent $(1-\alpha) \bar{y}_{2}$ on top of the verifiable first period cash flow $\alpha \bar{y}_{1}$.

\subsection{Investor Control in Financial Distress}

Suppose now that parties seek to attain an ex post efficient outcome in a financial distress state $\omega \in\{U, B\}$ by giving control to $I$, namely by setting $x^{I}=1$. We call this contract $I$-control. The incentive constraint (8) implies that ex post efficiency is attained provided $I$ 's payoff is maximized by liquidation in $B$ and by reorganization in $U$, namely:

$$
h_{R}^{I}(B) \leq h_{L}^{I} \leq h_{R}^{I}(U)
$$

We establish the following: 
Lemma 2 The optimal I-control contract satisfies (11) by pledging to I all reorganization proceeds, $h_{R}^{I}(\omega)=\alpha y_{2}(\omega)$ for $\omega \in\{U, B\}$, and an amount of liquidation proceeds equal to $h_{L}^{I}=L-S^{I}$, where $S^{I}=\max \left[0, L-\alpha \bar{y}_{2}\right]$ is the under-collateralization of I's claim.

Proof. To maximize repayment in reorganization, the contract sets the maximum feasible repayments $h_{R}^{I}(B)=\alpha \underline{y}_{2}$ and $h_{R}^{I}(U)=\alpha \bar{y}_{2}$. Because $\alpha \bar{y}_{2} \geq \alpha \underline{y}_{2}$, an appropriate $h_{L}^{I}$ can be found to satisfy (11). The highest such $h_{L}^{I}$ is equal to $\max \left[L, \alpha \bar{y}_{2}\right]$. We can thus rewrite $h_{L}^{I}=\max \left[L, \alpha \bar{y}_{2}\right]=$ $L-S^{I}$ where $S^{I}=\max \left[0, L-\alpha \bar{y}_{2}\right]$.

Given that $I$ is pledged all reorganization proceeds, his repayment in liquidation $h_{L}^{I}$ must ensure that in state $U$ the investor reorganizes with probability one. Two cases must be considered. If $\alpha \bar{y}_{2} \geq L$, efficient reorganization is so attractive for the investor that $I$ can be pledged all liquidation proceeds and still have the incentive to (efficiently) reorganize in $U$. If instead $\alpha \bar{y}_{2}<L$, the investor has a bias for liquidation. To remove such bias and induce him to make a socially efficient decision, his physical collateral must be reduced to $h_{L}^{I}=\alpha \bar{y}_{2}<L$. The amount $S^{I}=\max \left[L-\alpha \bar{y}_{2}, 0\right]$ therefore captures the under-collateralization of the investor's claim. Such under-collateralization allows $I$ to internalize the social benefit of reorganization.

From Lemmata 1 and 2 it follows that $I$-control is ex ante feasible, i.e. it fulfills (6), provided:

$$
\pi\left(\alpha \bar{y}_{1}+\bar{y}_{2}\right)+\frac{1-\pi}{2}\left[\alpha \bar{y}_{2}+\left(L-S^{I}\right)\right] \geq K
$$

When investor protection is strong, i.e. when $\alpha$ is high, contracts can give $I$ the incentive to resolve financial distress efficiently and (12) is met. If $\alpha=1$ then under-collateralization is unnecessary $\left(S^{I}=0\right)$ and $I$ can be pledged all cash flows, so the first best is attained. As $\alpha$ decreases, Equation (12) is less likely to be met because: i) fewer cash flows can be pledged to $I$, and ii) the extent of under-collateralization $S^{I}$ must increase, which both undermine break even.

\subsection{Entrepreneur Control in Financial Distress}

Consider now the case in which control is allocated to the entrepreneur, $x^{E}=1$, which we call E-control. In this case, the incentive constraint (8) implies that $E$ liquidates the firm in $B$ and reorganizes it in $U$ provided:

$$
\underline{y}_{2}-h_{R}^{E}(B) \leq L-h_{L}^{E} \leq \bar{y}_{2}-h_{R}^{E}(U) .
$$


We establish the following:

Lemma 3 The optimal E-control contract satisfies (13) by pledging to I all reorganization proceeds, $h_{R}^{E}(\omega)=\alpha y_{2}(\omega)$ for $\omega \in\{U, B\}$, and an amount of liquidation proceeds equal to $h_{L}^{E}=L-S^{E}$, where $S^{E}=(1-\alpha) \underline{y}_{2}$ is the under-collateralization of I's claim.

Proof. To maximize repayment following reorganization, the contract sets the maximum repayments $h_{R}^{E}(B)=\alpha \underline{y}_{2}$ and $h_{R}^{E}(U)=\alpha \bar{y}_{2}$. Because $(1-\alpha) \bar{y}_{2} \geq(1-\alpha) \underline{y}_{2}$, an appropriate $h_{L}^{E}$ can always be found to satisfy (13). The largest such $h_{L}^{E}$ is equal to $h_{L}^{E}=L-(1-\alpha) \underline{y}_{2}>0$. We can thus rewrite $h_{L}^{E}=L-S^{E}$ where $S^{E}=(1-\alpha) \underline{y}_{2}$.

To maximize repayment, $I$ is still pledged all reorganization cash flows. To induce $E$ to efficiently liquidate the firm in $B$ then, he must be paid his control rent $(1-\alpha) \underline{y}_{2}$ out of liquidation proceeds. The investor's claim is again under-collateralized, this time by the amount $S^{E}=$ $(1-\alpha) \underline{y}_{2}$. By Lemmata 1 and 3, E-control is then ex ante feasible provided:

$$
\pi\left(\alpha \bar{y}_{1}+\bar{y}_{2}\right)+\frac{1-\pi}{2}\left[\alpha \bar{y}_{2}+\left(L-S^{E}\right)\right] \geq K
$$

The difference with (12) lies in the extent of under-collateralization $S^{E}=(1-\alpha) \underline{y}_{2}$ required to induce ex post efficiency, which is generally different from the level $S^{I}$ prevailing under I-control. It is still the case, though, that implementing the first best under E-control becomes difficult at low $\alpha$. In general, at any level of $\alpha$, the most ex ante feasible way to attain ex post efficiency is to use the contract ( $I$ - or E-control) featuring the smallest under-collateralization.

\subsection{Stochastic Control in Financial Distress}

If $\alpha$ is so low that the first best cannot be attained under neither $I$-control nor $E$-control, ex ante break-even requires $E$ to sacrifice ex post efficiency. To do so, parties commit to sometimes terminating the firm upon default even if the state is $U$. The resulting over-liquidation generates an ex post cost, $\left(\bar{y}_{2}-L\right)$. In this parameter range, the use of a stochastic control structure can allow parties to minimize the frequency of inefficient liquidation.

We indeed establish the following:

Lemma 4 Depending on parameter values, either of the following two arrangements allows parties to attain a second best outcome:

i) Stochastic E-control: with probability $x^{E}$ the E-control contract of Lemma 3 is implemented; 
with probability $1-x^{E}$ the I-control contract of Lemma 2 is implemented, except that now I is pledged all liquidation proceeds, namely $h_{L}^{I}=L$;

ii) Stochastic I-control: the I-control contract of Lemma 2 is implemented, except that now repayment in liquidation is equal to $h_{L}^{I}=L-S^{I}$ with probability $\phi$, and $h_{L}^{I}=L$ otherwise.

Proof. The proof is in the Appendix, and follows immediately from Lemmata 2 and 3.

Consider, one at the time, the two contracts above. Under stochastic E-control, with probability $x^{E}$ the entrepreneur is in control and has the incentive to take an ex post efficient decision. With probability $\left(1-x^{E}\right)$ the investor is in control but since he obtains all liquidation proceeds, he always liquidates because in this range $\alpha \bar{y}_{2} \leq L$. For $x^{E}=1$ this contract is equivalent to $E$-control, and for $x^{E}=0$ it is equivalent to a straight debt contract that implements full deterministic liquidation ex post, in the spirit of Hart and Moore (1998). Investor break even can then be attained by setting $x^{E}=\widehat{x}^{E}$, whereby $\widehat{x}^{E}$ is implicitly defined as:

$$
\pi\left(\alpha \bar{y}_{1}+\bar{y}_{2}\right)+\frac{1-\pi}{2}\left\{\widehat{x}^{E}\left[\alpha \bar{y}_{2}+\left(L-S^{E}\right)\right]+\left(1-\widehat{x}^{E}\right) 2 L\right\}=K
$$

Ex ante financing is feasible for $x^{E} \leq \widehat{x}^{E}$. At the same time, lowering $x^{E}$ below $\widehat{x}^{E}$ reduces the ex post efficiency of stochastic E-control relative to deterministic liquidation. As a result, parties set $x^{E}=\widehat{x}^{E}$ in the optimal stochastic E-control contract.

In stochastic I-control the investor is always in control but he has correct incentives to reorganize only with probability $\phi$, whereby the contract sets $h_{L}^{I}=L-S^{I}=L-\alpha \bar{y}_{2}$. With probability $(1-\phi)$ all liquidation proceeds go to $I$, who always liquidates. For $\phi=1$ this arrangement is equivalent to $I$-control, and for $\phi=0$ it is equivalent to straight debt. Ex ante break even is then attained by setting $\phi=\widehat{\phi}$, whereby $\widehat{\phi}$ is implicitly defined as:

$$
\pi\left(\alpha \bar{y}_{1}+\bar{y}_{2}\right)+\frac{1-\pi}{2}\left\{\widehat{\phi}\left[\alpha \bar{y}_{2}+\left(L-S^{I}\right)\right]+(1-\widehat{\phi}) 2 L\right\}=K
$$

Ex ante financing is feasible for $\phi \leq \widehat{\phi}$. At the same time, lowering $\phi$ below $\widehat{\phi}$ reduces the ex post efficiency of stochastic I-control relative to deterministic liquidation. As a result, parties set $\phi=\widehat{\phi}$ in the optimal stochastic I-control contract.

Stochastic I-control is then preferred to stochastic E-control if and only if the former contract attains break even at a higher level of ex post efficiency, namely $\widehat{\phi} \geq \widehat{x}^{E}$. By comparing (15) and (16) it is easy to see that this is the case if and only if $S^{E} \geq S^{I}$. As in our previous analysis, 
parties choose $I$-control over E-control if and only if the investor is cheaper to incentivize than the entrepreneur.

Interestingly, in our setup the above two contracts always dominate an arrangement that, in the spirit of Aghion and Bolton (1992), sets a stochastic control allocation without exploiting undercollateralization. As we show in the proof of Proposition 1, relative to a simple randomization, under-collateralization generates efficiency gains both ex post and ex ante by harnessing the parties' superior information about the firm's reorganization value.

\subsection{Investor Protection and the Optimal Contract}

One main goal of our analysis is to study how the optimal contract and welfare vary with $\alpha{ }^{6}$

Proposition 1 There exist $\alpha_{I}, \alpha_{E}$, and $\alpha_{D}$ with $\min \left(\alpha_{I}, \alpha_{E}\right) \geq \alpha_{D} \geq 0$ such that:

i) for $\alpha>\max \left(\alpha_{I}, \alpha_{E}\right)$ parties attain the first best with either I- or E-control;

ii) for $\alpha \in\left[\min \left(\alpha_{I}, \alpha_{E}\right), \max \left(\alpha_{I}, \alpha_{E}\right)\right]$ parties attain the first best with $I$-control when $\alpha_{I} \leq \alpha_{E}$ and with E-control otherwise;

iii) for $\alpha \in\left[\alpha_{D}, \min \left(\alpha_{I}, \alpha_{E}\right)\right)$, parties attain the second best by using either stochastic $I$-control or stochastic E-control.

iv) For $0 \leq \alpha<\alpha_{D}$ the firm is not financed.

In case iii) the probability of liquidation in $\omega \in\{U, B\}$ monotonically increases in $\alpha$ and tends to one as $\alpha$ tends to $\alpha_{D}$. When the firm is financed, it is weakly optimal to set $D=K$, even if setting any $D \geq K$ is allowed.

The proof, which formally defines thresholds $\alpha_{I}, \alpha_{E}, \alpha_{S}$ and $\alpha_{D}$, is in the Appendix. As in Aghion and Bolton (1992) the choice between entrepreneur and investor control is a key dimension in financial contract design. The novel idea here is that: i) under-collateralization is required for the resolution of financial distress to be first best efficient, and ii) investor protection $\alpha$ shapes the efficiency of contractual resolutions of financial distress by shaping the cost of under-collateralization and more generally the pledgeability of cash flows.

If $\alpha$ is high, i.e. as in case $i$ ), under-collateralization is small or unnecessary and parties reach the first best with either $I$ - or E-control. If $\alpha$ is intermediate, i.e. as in case $i i)$, parties may attain the first best with $I$ - or E-control but not with both. In this range, $I$-control is used if and only if

\footnotetext{
${ }^{6}$ To preserve our focus on contracts, Proposition 1 only reports which contractual typology is used as a function of $\alpha$. Information on total debt capacity at different levels of $\alpha$ can be found in Appendix 1 .
} 
its required under-collateralization $S^{I}$ is lower than that required under $E$-control. The first best is attained by giving control to the party that is cheaper to incentivize. Depending on parameter values, such party is the investor when $\alpha_{I} \leq \alpha_{E}$, or the entrepreneur when $\alpha_{I}>\alpha_{E}$.

If $\alpha$ is so low that the first best cannot be attained under neither $I$-control nor E-control, i.e. as in case $i i i$ ), ex ante break even requires $E$ to sacrifice ex post efficiency. To do so, $E$ writes a stochastic control contract whereby non-repayment leads to inefficient liquidation with some probability, which facilitates break even when $L>\alpha \bar{y}_{2}$. In this range, as investor protection decreases toward $\alpha_{D}$ the probability of automatic liquidation increases monotonically and the optimal arrangement converges to a standard straight debt contract whereby the firm is always liquidated in financial distress, namely $x^{E}=\phi=0$. Intuitively, if $\alpha$ is low then tunneling of the firm by $E$ is a major problem for $I$, creating pressure for a piecemeal sale. Thus, in our model the automatic foreclosure on the debtor's physical assets depends endogenously on $\alpha^{7}{ }^{78}$

The proof of Proposition 1 formally shows that these findings are robust to allowing for lack of commitment and ex post renegotiation. Introducing these features only reduces investor repayment in $G$ but it does not affect the resolution of financial distress. The reason is that in $\omega \in\{U, B\}$, either the outcome is ex post efficient or $E$ lacks the resources to renegotiate. ${ }^{9}$ As a result, renegotiation only increases all thresholds $\alpha_{I}, \alpha_{E}, \alpha_{S}, \alpha_{D}$, but it neither affects the comparison of different contracts nor the role of investor protection. For similar reasons it is not helpful for the entrepreneur to borrow $D>K$. The conventional benefit of extra lending, $D>K$, is to provide $E$ with funds to renegotiate, reducing ex post inefficiencies [see Hart and Moore (1998)]. In our model, however,

\footnotetext{
${ }^{7}$ In principle, since parties are symmetrically informed about the firm's reorganization value, the contract could include a revelation game [Maskin (1999)] of the following sort. The parties separately report the state of nature. The contract specifies that if both reports are $U$ the firm is reorganized, if both reports are $B$ the firm is liquidated. If reports disagree, the firms is liquidated and the proceeds are paid to charity. This contract induces a truth telling Nash equilibrium implementing the first best with the appropriate assignment of payouts. Unfortunately, however, the players may also coordinate on two other Nash equilibria (always say $B$ or always say $U$, where the latter equilibrium could be eliminated by fining the investor ex post for having lied). As a result, whenever feasible, E-control and $I$-control dominate this revelation game. When instead both $E$ and $I$-control are unfeasible, the revelation game may improve upon straight debt, although the revelation game itself is not feasible for low $\alpha$ because in financial distress it repays at most $(1 / 2)\left(\alpha \bar{y}_{2}+L\right)$ to $I$. Crucially, in Section 4 we shall see that when $E$ borrows from multiple creditors $I$-control always (at least weakly) dominates the revelation game.

${ }^{8}$ Assumption A.2 reduces the number of cases to consider by implying that stochastic E-control is feasible at lower levels of $\alpha$ than stochastic I-control. The main features of contract choice remain valid if A.2 is relaxed.

${ }^{9}$ As formally shown in the Appendix, renegotiation in our model occurs by Nash bargaining. Whenever the contract implements an ex post inefficient allocation, $E$ and $I$ have the opportunity to renegotiate it away. The entrepreneur then obtains a share $e \in[0,1]$ of the renegotiation surplus while $I$ obtains the remaining share $(1-e)$ of it. This formulation covers both the case in which $E$ can make a take it or leave it offer to $I(e=1)$ and the case in which $I$ has all the bargaining power $(e=0)$. As the proof of Proposition 1 makes clear, since the optimal contract implements an efficient outcome in financial distress, renegotiation can only arise in state $G$ after strategic default.
} 
ex post efficient outcomes can be attained without renegotiation by using incentive schemes.

Our optimal contract is related to proposals suggesting automatic conversion of debt into equity upon default [Aghion, Hart and Moore (1992)], which is another way of pledging the creditor not only physical collateral but also reorganization proceeds. We discuss the AHM proposal in greater detail in Section 6. Here we stress that under automatic conversion of debt into equity the investor obtains the same share of liquidation and reorganization proceeds, thereby inefficiently liquidating the firm whenever $\alpha \bar{y}_{2}<L$. By contrast, the under-collateralization of the investor's claim removes his liquidation bias, inducing him to see the benefit of efficient reorganization also when $\alpha \bar{y}_{2}<L$. From an ex post perspective, under-collateralization can provide an efficiency justification for violations of priority in favor of junior creditors (not debtors).

Although these results rationalize some desirable features of creditor control, they also suggest that under some conditions I-control is strictly dominated by E-control, casting doubts on the efficiency of the former. Additionally, conventional wisdom argues that inter-creditor conflicts may magnify creditors' bias toward liquidation, reducing the appeal of $I$-control. To address these issues, we now study the multiple creditors case.

\section{Multiple Creditors and Creditor Control}

We first address the possibility for the optimal debt structure to solve conflicts among existing creditors such as those leading to inefficient runs [e.g. Jackson (1986)], and those between secured and unsecured creditors [e.g. Manove, Padilla and Pagano (2001)]. In Section 4.2 we discuss the conflict between old and new creditors [e.g. Gertner and Scharfstein (1991)].

\subsection{The Optimal Debt Structure}

We introduce some notation and define the contract space. Suppose that $E$ raises funds from $j=1, \ldots, N$ creditors. Then, denote by $\rho_{j} \in\{0,1\}$ an indicator variable taking value 1 if in state $G$ the entrepreneur repays creditor $j$ in full and 0 otherwise. Adapting our previous notation, let $x^{j}$ be the probability that creditor $j$ controls the liquidation/reorganization decision; let $\lambda^{j}(\omega)$ be the probability of liquidation chosen by creditor $j$ in state $\omega$ when in control; and let $h_{L}^{j, j^{\prime}}$ and $h_{R}^{j, j^{\prime}}(\omega)$ be the amount of liquidation and reorganization proceeds, respectively, distributed to creditor $j$ in state $\omega$ when creditor $j^{\prime}=1, \ldots, N$ is in control. 
Given these definitions, $E$ simultaneously proposes to each creditor $j$ a contract specifying:

i) the amount $D_{j}$ that $j$ lends to $E$, where $\sum_{j} D_{j}=K$;

ii) the probability $\lambda\left(\rho_{1}, \ldots, \rho_{N}\right)$ of liquidation in state $G$ for any profile of default decisions $\left(\rho_{1}, \ldots, \rho_{N}\right)$;

iii) the probability $x^{j}$ with which $j$ is in control in $\omega \in\{U, B\}$, with $\sum_{j} x^{j}+x^{E}=1$;

iv) repayments $d_{t}^{j}(\rho)$ in $G$. In state $\omega \in\{U, B\}$ the contract specifies repayments $h_{L}^{j, j^{\prime}}$, $h_{R}^{j, j^{\prime}}(\omega)$ promised to $j$ in liquidation and reorganization when $j^{\prime}$ is in control.

Once more, $h_{L}^{j, j^{\prime}}$ can be a random variable, and one can define the expected repayment $d_{t}^{j}(\omega)$ received by investor $j$ in state $\omega \in\{U, B\}$ by using $h_{L}^{j, j^{\prime}}, h_{R}^{j, j^{\prime}}(\omega)$ according to equations (2) and (3). The feasibility conditions are $\sum_{j} d_{1}^{j}(0, \ldots, 0) \leq \alpha \bar{y}_{1}+\lambda(0, \ldots, 0) L, \sum_{j} d_{2}^{j}\left(\rho_{1}, \ldots, \rho_{N}\right) \leq$ $\alpha \bar{y}_{2}\left[1-\lambda\left(\rho_{1}, \ldots, \rho_{N}\right)\right], \sum_{j} h_{R}^{j, j^{\prime}}(\omega) \leq \alpha y_{2}(\omega)$ for all $j^{\prime}, \sum_{j} h_{L}^{j, j^{\prime}} \leq L$ for all $j^{\prime}$, and $\sum_{j} d_{1}^{j}(1 \ldots, 1) \leq$ $\bar{y}_{1}$. Each creditor must break even.

\subsubsection{The Two-Tier Debt Structure}

Given the above contract space, $E$ can replicate the one creditor outcome of Section 2 under any number $N>1$ of creditors. To see this, consider the threshold $\alpha_{I}$ of Proposition 1 . We find:

Lemma 5 For $\alpha \geq \alpha_{I}$, the entrepreneur can replicate the one-creditor outcome under $N>1$ creditors by issuing to each creditor $j$ an $I$-control contract that in state $\omega \in\{U, B\}$ gives each creditor control of the liquidation decision with probability $x^{j}=1 / N$, pledges him an amount $h_{R}^{j, j^{\prime}}(\omega)=\alpha y_{2}(\omega) / N$ of the firm's reorganization proceeds and an amount $h_{L}^{j, j^{\prime}}=\min \left(\alpha \bar{y}_{2}, L\right) / N$ of the firm's liquidation proceeds. As in the one creditor case, in state $G$ the contract features $\lambda(1, \ldots, 1)=0$ and full liquidation otherwise, and the resulting total repayment $\left(\alpha \bar{y}_{1}+\bar{y}_{2}\right)$ can be arbitrarily split among the $N>1$ creditors.

The proof is in the Appendix. By pledging creditors the reorganization proceeds and by undercollateralizing their claims, $E$ can provide each of them with the incentive to efficiently reorganize or liquidate the firm. These incentives foster unanimity: all creditors want to take an efficient decision when in control. As a result, $E$ replicates the one creditor outcome of $I$-control when $N>1 .{ }^{10}$ In

\footnotetext{
${ }^{10}$ In Lemma 5 we have assumed that creditors are entitled to obtain a share of the total proceeds from liquidation rather than the proceeds from liquidating a specific fraction of the firm. All of our results would go through under
} 
this sense, creditor runs and lazy creditor problems are a by-product of a sub-optimal debt structure rather than an intrinsic problem of financial distress. In this model, creditors obtain control with some probability, but to ease intuition such probability can be viewed as the deterministic fraction of the firm's assets that the creditor controls upon default. In the current risk-neutral setting, and under the additional assumption of constant returns to scale, these two interpretations are exactly equivalent.

Of course, when $\alpha<\alpha_{I}$ the scheme of Lemma 5 is not feasible because creditors are just too biased toward liquidation. As a result, $E$ must commit to sometimes liquidating the firm ex post to attain break even ex ante. It is easy to see that $E$ can do so and replicate the one creditor outcome by issuing debt claims that mimic those described in Proposition 1 . This allows $E$ to finance the project for $\alpha \geq \alpha_{D}$.

Remarkably, though, it turns out that by borrowing from two classes of creditors the optimal debt structure can: i) improve upon the one-creditor outcome, and ii) avoid using E-control altogether. The term creditors' class refers to any subset of creditors obtaining the same contract. We consider debt structures consisting of two classes of creditors $C$ and $\bar{C}$, where $|C \cup \bar{C}|=N$, such that each creditor $j \in C$ obtains control in financial distress (with some probability) while each creditor $j \in \bar{C}$ never obtains control.

If creditors cannot renegotiate, an optimal arrangement is described below:

Proposition 2 Denote by $\widehat{\alpha}_{I}$ the solution to the Equation:

$$
\pi\left(\widehat{\alpha}_{I} \bar{y}_{1}+\bar{y}_{2}\right)+(1-\pi)\left(\widehat{\alpha}_{I} \bar{y}_{2}+L\right) / 2=K
$$

where we have $\widehat{\alpha}_{I} \leq \min \left(\alpha_{I}, \alpha_{E}\right)$. Then, for $\alpha \geq \widehat{\alpha}_{I}, E$ attains the first best by borrowing from 2 creditors $j=1,2(N=2)$ under a two-tier debt structure where:

1) Creditor 1 obtains control in $\omega \in\{U, B\}$ under the I-control contract of Lemma 2.

2) Creditor 2 never has control in $\omega \in\{U, B\}$, obtains no reorganization proceeds, $h_{R}^{2,1}(\omega)=0$, and obtains an amount $h_{L}^{2,1}=S^{I}=\max \left(0, L-\alpha \bar{y}_{2}\right)$ of liquidation proceeds.

As with one creditor, in state $G$ the contract features $\lambda(1, \ldots, 1)=0$ and full liquidation otherwise. Total repayment $\left(\alpha \bar{y}_{1}+\bar{y}_{2}\right)$ can be arbitrarily split among the 2 creditors.

the latter, alternative assumption. We proceed with the former assumption because, as we shall see, it is consistent with a key feature of the optimal debt structure with multiple creditors, namely that some creditors are entitled to obtain some of the proceeds from liquidating assets that only other creditors have the right to liquidate. 
This is the central result of our analysis. Creditor 1 , belonging to class $C$, lends under an $I$ control contract. Creditor 2, belonging to class $\bar{C}$, has no control rights, obtains no reorganization proceeds, but is claimant to a share of liquidation proceeds. This separation between the right to control the firm upon default and the right to cash in some liquidation proceeds allows contracts to divorce the provision of incentives from total repayment, thereby reducing the incentive costs of $I$-control. To see this, suppose that $\alpha \bar{y}_{2}<L$. Then, because liquidation proceeds are easier to pledge than reorganization cash flows, efficient reorganization requires under-collateralization $S^{I}$. With the single class of debt of Lemma 5 , this is attained by under-collateralizing each of the $N$ creditors by $S^{I} / N \equiv\left(L-\alpha \bar{y}_{2}\right) / N$ and by redistributing to $E$ the aggregate amount of physical collateral $L-\alpha \bar{y}_{2}$. As shown by expression (12) such under-collateralization reduces creditors' repayment in liquidation, thereby reducing debt capacity. If instead $E$ borrows from two creditors where only one of them holds liquidation rights under an $I$-control contract, the amount $S^{I}$ can be redistributed to the non-controlling creditor, and not to $E$, thereby maximizing creditors' repayment. Formally, with two classes creditors as a whole obtain $(1 / 2)\left(\alpha \bar{y}_{2}+L\right)$ upon default, as opposed to $(1 / 2)\left(\alpha \bar{y}_{2}+L-S^{I}\right)$ under a single debt class. Note that $(1 / 2)\left(\alpha \bar{y}_{2}+L\right)$ is the maximum that can be possibly repaid in financial distress under a first-best optimal reorganization policy because the whole of liquidation proceeds $L$ are pledged to creditors in the aggregate.

The above result is obtained in the simplest case where there are two creditors and one of them is given the same $I$-control contract of Lemma 2, but the same result more generally holds under $N>1$ creditors and arbitrary repayments so long as: i) each controlling creditor is given the incentive to efficiently reorganize the firms, and ii) the non-controlling creditors obtain all the remaining reorganization and liquidation proceeds.

There are two key implications. First, introducing a second debt class allows parties to attain the first best for a (weakly) larger set of investor protection values $\alpha$ relative to the one-creditor outcome of Proposition 1. This is strictly the case when $\min \left(\alpha_{I}, \alpha_{E}\right) \cdot \bar{y}_{2}<L$, in which case under a single creditor under-collateralization is necessary to attain the first best.

Second, Proposition 2 also implies that - unlike in the single creditor case - with two classes of debt $I$-control is always optimal ex post and always dominates E-control in terms of ex ante feasibility. Indeed, under E-control the under-collateralization $S$ must necessarily be paid back to $E$, reducing repayment in financial distress strictly below $(1 / 2)\left(\alpha \bar{y}_{2}+L\right)$, with clear ex ante costs. In sum, under-collateralization naturally implies: i) the optimality of a second, passive debt class and ii) the optimality of I-control. 
The redistribution $S$ of liquidation proceeds in favor of creditors without control rights may be consistent with either of two features of real-world lending. First, consistent with evidence in Franks and Nyborg (1996), in the context of floating charge financing there may be several creditors (e.g. trade creditors) - other than the floating charge holder - that lend under physical collateral. Second, consistent with evidence in Franks and Torous (1994) on distressed exchanges in the U.K., $S$ may represent the extent of violations of absolute priority in favor of junior creditors (as opposed to equity holders). Once again, violating priorities in favor of junior creditors is useful because it removes the controlling creditor's liquidation bias while preserving the firm's debt capacity.

One objection to Proposition 2 is that ex post collusion among creditors can undermine the benefit of issuing two debt classes. This is because, whenever creditors as a group lose from reorganization (i.e. $\alpha \bar{y}_{2}<L$ ), they may collude against $E$ and liquidate the firm in state $U$. A realistic way in which collusion may arise is consolidation of creditors' claims in secondary debt markets by the creditor in control (or any other investor). Additionally, we need to study what happens when $\alpha<\widehat{\alpha}_{I}$ to see whether creditor control is also optimal when the first best is not feasible. We address these issues next.

\subsubsection{Collusion among Creditors and the Optimal Debt Structure}

Suppose that $\alpha \geq \widehat{\alpha}_{I}$ and the debt structure is the one of Proposition 2, except that now there is more than one creditor without control rights, namely $|\bar{C}|>1$. Suppose that each creditor $j \in \bar{C}$ without control is pledged an amount $\left(L-\alpha \bar{y}_{2}\right) /|\bar{C}|$ of liquidation proceeds. Then, the creditor in control may try to consolidate the claims of the other creditors and then inefficiently liquidate the firm. Critically, it is easy to show that if the creditors not in control are fully dispersed, namely $|\bar{C}|=+\infty$, a standard holdout problem arises [Gertner and Scharfstein (1991)]. Expecting consolidation of claims to occur, each of these creditors is only willing to sell if the price of the claim is not smaller than the claim's value under liquidation. But then, of course, the creditor in control has no incentive to buy any claim and liquidate the firm. His benefit from doing so is zero at best.

The implication is that $E$ can set up the debt structure in such a way as to avoid any ex post consolidation of claims. This is achieved by fully dispersing the claims of the creditors not in control, which ensures ex post efficient reorganization. ${ }^{11}$ We then find that:

\footnotetext{
${ }^{11}$ We have abstracted from the potential costs arising from creditors' dispersion. For example, Bris and Welch (2005) note that creditors' dispersion may make them vulnerable to the debtor, eventually undermining break even.
} 
Corollary 1 E cannot improve upon the following outcome/debt structure:

1) For $\alpha \geq \widehat{\alpha}_{I}$, the first best is attained by giving to one large creditor the $I$-control contract of Lemma 2 (i.e. $|C|=1$ ), and by distributing the remaining $S^{I}=L-\alpha \bar{y}_{2}$ liquidation proceeds to a dispersed creditor class (i.e. $|\bar{C}|=\infty$ ).

2) For $\alpha_{D} \leq \alpha<\widehat{\alpha}_{I}$, the second best outcome is attained by giving one large creditor the stochastic I-control contract of Lemma 4 (i.e. $|C|=1$ ) and by distributing (with probability $\phi / 2$ ) the amount $S=L-\alpha \bar{y}_{2}$ of liquidation proceeds to a dispersed creditor class (i.e. $\left.|\bar{C}|=\infty\right)$. The probability $\phi$ is determined as the solution to:

$$
\pi\left(\alpha \bar{y}_{1}+\bar{y}_{2}\right)+\frac{1-\pi}{2}\left\{\phi\left(\alpha \bar{y}_{2}+L\right)+(1-\phi) 2 L\right\}=K
$$

3) If $\alpha<\alpha_{D}$, the firm is not financed.

The proof is in the Appendix. The proposition does not report the optimal arrangement in state $G$, as it is the same as in Proposition 2. Turning to the optimal resolution of financial distress, when investor protection is sufficiently large $\left(\alpha \geq \widehat{\alpha}_{I}\right)$ the two-tier debt structure of Proposition 2 attains the first best provided the creditor class without liquidation rights is fully dispersed. The creditor class with controlling rights can then be fully concentrated into a single, large creditor who has a large stake in reorganization. ${ }^{12}$

When investor protection decreases below $\widehat{\alpha}_{I}$, the debtor must commit to sometimes liquidating the project by using a stochastic $I$-control contract. The presence of a second debt class facilitates break even relative to the one creditor case, though, as one can see by comparing equation (19) with equation (16). Additionally, in the presence of a second debt class the incentive costs of $I$-control disappear, so E-control is never optimal, as in Proposition 2.

The above results do not rely on constant returns to scale. In particular, they continue to hold when the firm's assets are complementary in that they feature increasing returns to scale.

In a previous version we have formally studied this possibility and showed that in that case the debtor faces a trade-off between the ex post benefit of dispersing claims and its ex ante cost, reducing repayment. The results are available upon request.

${ }^{12}$ We have also formally proved that concentrating control rights on a single large creditor is strictly optimal when collusion among creditors arises via exogenous random coalition formation. In this case, concentration of control reduces the probability that any given coalition of creditors without control can bribe the controlling creditor into inefficient liquidation. The results are available upon request.

The optimal debt structure is also immune to other potential problems. For instance, since $I$-control gives the creditor with control rights the incentive to do the efficient thing, it also prevents him from threatening other creditors that he will inefficiently reorganize or liquidate the firm, so as to force them to accept an opportunistic distressed exchange. The intuition is that these threats are not credible, as they are not in the controlling creditor's interest. 
In this case, the concentration of liquidation rights on a single creditor who is given the incentive to efficiently reorganize also allows him to internalize asset complementarities, which would be disregarded if atomistic creditors were jointly exercising control.

Our results highlight two novel features. First, rather than protecting creditors against the debtor's strategic default [Bolton and Scharfstein (1996), Diamond (2004)], creditor dispersion in our model protects the debtor against inefficient liquidation. One implication is that, while in existing theories creditor dispersion is especially valuable at low levels of investor protection (where strategic default is problematic) in our model creditor dispersion is valuable at relatively high levels of investor protection, where rescuing profitable firms ex post is valuable.

Second, our model rationalizes the coexistence of two classes of debt, one fully concentrated on a large creditor who has control rights (e.g. a bank), the other fully dispersed and without control rights (e.g. public debt such as bonds, or trade creditors). Such coexistence should be observed at relatively high levels of investor protection. Existing work on multiple investors [e.g. Dewatripont and Tirole (1994), Berglöf and von Thadden (1994), Winton (1995), Park (2000)] neither studies the role of concentration in different classes of debt, nor the role of investor protection ${ }^{13}$; at the same time, existing work on debt structure [e.g. Diamond (1991, 1993); Rajan (1992)] studies the choice between bank and arm's length finance, not their coexistence.

\subsection{Optimal Debt Structure with Arrival of New Creditors}

It is well known that the conflict between existing and new creditors may result in under- as well as over-investment [e.g. Myers (1977), Jensen and Meckling (1976), Gertner and Scharfstein (1991)]. In a previous version of the paper, we showed that the debt structure of Corollary 1 is, with minor modifications, optimal also in a setting where new creditors arrive in the debt structure to reinvest

\footnotetext{
${ }^{13}$ There are also other differences between our model and these papers. In Dewatripont and Tirole (1994), the coexistence of debt and equity allows the debt structure to give incentives to the manager to exert effort and to an investor to liquidate the firm after bad performance, so that in the absence of a managerial effort choice, a single security would be optimal. In our model instead, the two debt classes give the creditor the incentive to pursue the efficient reorganization policy in financial distress.

Berglöf and von Thadden (1994) also stress the role of managerial moral hazard by showing that issuing short and long term debt might maximize the debtor's incentive to repay. In our model instead, the issue is not to incentivize the manager but the investor and the presence of a second security allows to do so at zero ex ante cost.

In a costly-state-verification model Winton (1995) derives the optimal mix of secured and unsecured claims as a function of exogenous verification costs. In our model instead the ex ante and ex post costs of different claims are determined endogenously as a function of imperfect enforcement.

In a model where different investors have access to different monitoring technologies, Park (2000) studies the optimal debt structure when the moral hazard problem is particularly severe and finds that it is optimal for the entrepreneur to borrow from two classes of debt. In contrast, we derive the optimal debt structure in a model without monitoring and in our model investors do not differ ex ante.
} 
in a financially distressed firm at $t=1$. In this case, the controlling creditor is also given the right to approve supra-priority financing and his under-collateralization is designed to induce him to internalize the upside of reinvestment. In the interest of space, we make these results available in an online appendix.

\section{Discussion}

\subsection{Floating Charge Financing in the U.K.}

We now show that our optimal debt structure rationalizes the salient features of the way in which financial distress is contractually resolved in the U.K. Franks and Sussman (2005a) document that in the U.K. financial distress is resolved by contract with the extensive use of floating charge financing. As in our optimal debt structure, upon default a large creditor (typically a bank) is given control rights over the reorganization vs. liquidation decision. ${ }^{14}$ This creditor is also given a floating charge, which is a security that covers not only certain specific physical assets, but it can also be extended to cover the whole pool of the company's assets, including intangibles and working capital (i.e. cash, receivables, future cash flows). In the context of our optimal contract, the floating charge effectively represents a claim over the company's reorganization proceeds $\alpha \bar{y}_{2}$. Crucially, the creditor in control is often given not only a floating charge but also a fixed charge, which allows him to repossess physical collateral in case of liquidation. Since fixed charges are usually senior to the floating charge, the fixed charge allows the creditor in control to be senior in liquidation, ahead of any preferential claims and unsecured creditors. In the context of our model, the fixed charge represents the claim over (some of) the company's liquidation proceeds $L-S$. Finally, and again consistent with our model, the rest of the lending is dispersed among many small creditors.

Note that, to implement our optimal debt structure in the real world, it is not necessary to give all reorganization cash flows to the floating charge holder. It is only necessary to pledge him a disproportionately larger share of reorganization cash flows relative to the other creditors. In practice, he can simply be given a sufficiently large amount of the debt's face value, which, together with the floating charge, effectively acts as an equity stake. That is, upon reorganization, the floating charge holder obtains a share of the reorganized firm which is equal to his share of the

\footnotetext{
${ }^{14}$ Upon deciding for reorganization, the floating charge holder leaves the management in control. Upon deciding for liquidation, he usually appoints a professional agent, e.g. a receiver. The receiver assumes all the powers of the company's board of directors on behalf of the floating charge holder [e.g. Davies (1997, p. 385)].
} 
firm's outstanding debt.

In our model, these features of floating charge financing are instrumental to providing the controlling creditor with correct incentives to efficiently resolve financial distress. In line with this possibility, Franks and Sussman (2005a) document that in the U.K. floating charge financing works very well, mitigating the problems usually associated with creditor control. In particular, there are no inefficient runs and the controlling creditor's typical response to financial distress is an attempt to rescue the firm rather than to liquidate it automatically. Furthermore, while floating charge financing in the U.K. is sometimes held responsible for under-investment in financial distress [e.g. Franks, Nyborg and Torous (1996)], our results suggests this may be due to the limited viability of supra-priority financing in the U.K., given U.K. courts' ambiguous stance towards it [e.g. Davies (1997)]. As our model shows, these and other limitations to supra-priority financing may directly trigger under-investment. Thus, our analysis indicates that one simple reform strategy in the U.K. may be to just allow debt structures to combine floating charge with supra-priority financing. ${ }^{15}$

\subsection{Contractual Resolutions of Distress Around the World}

Our model has also several cross country implications. First, it predicts that contractual resolutions of financial distress should work better, both in terms of ex ante and ex post efficiency, in countries with stronger investor protection, particularly when creditors are legally allowed to use floating charges. The notion of investor protection relevant for this prediction is broader than that of creditor rights and includes shareholder protection against managerial self-dealing and tunneling. The reason is that upon reorganization the floating charge holder ends up with an equity-like claim. These predictions are consistent with Djankov et al. (2008a), who document that a purely contractual resolution of financial distress such as foreclosure by the senior creditor works well both in terms of ex post and ex ante efficiency, and especially so when the senior creditor is legally allowed to finance under a floating charge contract. They also document that this contract works best in common law and richer countries. To the extent that these countries also have higher investor protection, this evidence is consistent with our predictions. ${ }^{16}$

One question then arises, given the benefits of floating charge, why isn't such contract used

\footnotetext{
${ }^{15}$ See, e.g., Proposition $A 1$ in the online appendix. Of course one may also use a more top down approach, legally reducing the power of the floating charge holder to block reinvestment and restructuring in financial distress. The U.K. Enterprise Act of 2002 is an example of this second type of approach, whose consequences are yet to be fully evaluated.

${ }^{16}$ Other papers stress that also court supervised procedures work better in countries with more efficient legal systems, see for instance Povel (1999), Ayotte and Yun (2009) and Gennaioli and Rossi (2010).
} 
everywhere in the world? Since our goal is to rationalize the observed debt structures to resolve financial distress, we cannot directly address this question, which bears on the comparison of contractual resolutions of financial distress with formal bankruptcy procedures. At the same time, our analysis can suggest some possible avenues to address this question. The most direct explanation is that in many countries the floating charge is legally forbidden [Djankov et al. (2008a)]. More subtly, the floating charge may be hard to transplant, being as it is the end result of a long process of precedent accumulation that is specific to certain common law systems [Franks and Sussman (2005b)]. Perhaps more interestingly, more developed countries where floating charge works well may also be able to implement more efficient formal bankruptcy procedures, as suggested by Djankov et al. (2008a). ${ }^{17}$

\section{Conclusions}

We study theoretically the economics of the optimal contractual resolution of financial distress. Our results rationalize in an optimal contracting setup the optimality of floating charge financing and its efficiency at high levels of investor protection. Our emphasis on contracts is novel. Prior theoretical work on financial distress [e.g. Berglöf et al (2010), Ayotte and Yun (2009), and Povel (1999), among others] seeks in fact to rationalize the optimality of observed state-provided bankruptcy procedures mandating entrepreneurial control under court supervision. We complement these studies by rationalizing which debt structures are used when parties are willing and free to resolve financial distress by contract.

From a broader perspective, our results on optimal bankruptcy mechanisms can provide some useful insight for bankruptcy reform in countries where there is dissatisfaction with the working of existing bankruptcy procedures. In particular, it may be desirable to include a mechanism mimicking the two-tier debt structure implemented by the floating charge in the bankruptcy code and allow parties to opt for it. In fact, floating charge financing may have some advantages with respect to the two leading academic proposals for bankruptcy reform - the use of cash auctions [Baird (1986), Jensen (1989)] and the use of options [Bebchuk (1988); AHM (1992)].

Consider first the AHM proposal. Its basic idea is that, when a firm goes bankrupt, all the

\footnotetext{
${ }^{17} \mathrm{~A}$ fourth possibility is that other private mechanisms could mimic floating charge financing, even in the shadow of formal bankruptcy procedures. Some evidence along these lines comes from Brunner and Krahnen (2008), who show that in Germany (where the floating charge is not allowed and liquidation is the standard insolvency procedure) the presence of small pools of banks increases the probability of workout success. Also in this case large creditors such as banks successfully coordinate out-of-court restructurings.
} 
firm's debts are cancelled, and all claims are converted into equity. In line with Bebchuk (1988), former claim-holders are either allocated equity in the new company (in the case of senior creditors) or given an option to buy equity (in the case of junior creditors or shareholders), according to the amount/priority of their claims. Then, cash and non-cash bids are solicited for all or part of the new firm. After the options have expired, the new shareholders vote on whether to select one of the cash bids or maintain the company as a going concern, either under existing management or under some alternative management team. The firm then exits from bankruptcy.

Formally, one can map this proposal into our model by noting that the former amounts to: 1) giving secured creditors (i.e. those with a claim to the liquidation value $L$ ) all the equity in the firm, and 2) giving unsecured creditors as well as shareholders (namely $E$ ) the option to post a non-cash bid for the firm. In the aggregate, secured creditors will never accept an offer that is less than $L$, the liquidation value of the firm. If $E$ and junior creditors do not exercise their options, secured creditors will efficiently reorganize if and only if $\alpha \bar{y}_{2}>L$, as already shown in Section 3. Accordingly, if junior claimants post a non cash bid of $\alpha \bar{y}_{2}$, secured creditors will only accept the bid if the state is $U$ and $\alpha \bar{y}_{2}>L$. As a result, our model rationalizes the optimality of the AHM mechanism when investor protection is sufficiently strong.

When instead $\alpha \bar{y}_{2}<L$ investor protection is not that strong, and under the AHM proposal the firm would be inefficiently liquidated. Our model suggests that one way to avoid this problem is to under-collateralize the claim of the secured creditor by the amount $S$, which in turn should be distributed to a new class of creditors (holding neither equity nor options) in such a way as not to affect the reorganization v. liquidation decision.

Consider now cash auctions. The idea is to put bankrupt firms on the block, collect cash bids from the public and sell the firm to the highest bidder [Baird (1986), Jensen (1989)]. The highest bidder then takes control of the firm, and decides whether to keep it as going concern, or liquidate it piecemeal. In our framework, allowing insiders to raise cash from public (stock) markets to finance a cash bid will result in over-liquidation if investor protection is low. Indeed, if a potential buyer proposes a reorganization plan, financial markets will only lend him an amount that reflects the expected value of the reorganized firm to them, namely up to $\alpha \bar{y}_{2}$, resulting in over-liquidation whenever $\alpha \bar{y}_{2}<L$. Once more, the problem is that cash auctions do not exploit under-collateralization.

Although floating charge may have these advantages over existing proposals, it is not panacea in and of itself. In particular, we would expect this mechanism (but also, and for the same reasons, 
the other proposals) to provide an efficient resolution of financial distress only when investor protection is sufficiently strong. Intuitively, attempts to export the flexible bankruptcy procedures of developed economies to countries plagued by poor legal infrastructure may result in both ex ante and ex post inefficiencies, consistent with the evidence in Franks and Lóránth (2006) and Lambert-Mogilianski et al. (2007).

A more fundamental implication of our results is that the problems usually associated with creditors' multiplicity, rather than being intrinsic problems of financial distress, may be just the by-products of the firms' debt structure. Within the traditional, ex post approach to bankruptcy, our analysis thus raises the question, why don't debt structures around the world always cope with problems of creditors' control and multiplicity? As previously discussed, one reason for the use of inflexible debt structures may just be the presence of legal restrictions to floating charge financing, or low investor protection. More fundamentally, floating charge may be costly because of other frictions that we have not explicitly modelled, for instance when not only voluntary creditors, but also tort creditors and workers need to be protected. ${ }^{18} \mathrm{~A}$ formal modeling of such potential failures of floating charge financing is clearly beyond the scope of our paper. In future research, it would be interesting to explicitly model the costs of floating charge and the choice between formal bankruptcy and contracts. Well beyond our model, though, the general message of our analysis is that the benchmark against which bankruptcy procedures should be evaluated is not the "war of all against all' depicted by the traditional approach to bankruptcy, but the much more orderly process implemented by floating charge financing.

\footnotetext{
${ }^{18}$ These third parties may be not only tort-creditors or workers [e.g. as in Bolton and Rosenthal (2002)], but also specialized input suppliers or non-exclusive contractors [e.g. as in Bisin and Rampini (2006)].
} 


\section{Appendix 1: Proofs}

Proof of Proposition 1 and of Lemma 4. We first study the case with full commitment and no renegotiation; later we relax these assumptions. The proof of Lemma 4 is indicated in the body of the proof below.

Case 1: optimal contract when $D=K$. Equation (12) says that $I$-control is feasible provided:

$$
\pi\left(\alpha \bar{y}_{1}+\bar{y}_{2}\right)+\frac{1-\pi}{2}\left\{\alpha \bar{y}_{2}+L-\max \left[L-\alpha \bar{y}_{2}, 0\right]\right\} \geq K
$$

The left-hand side decreases in $\alpha$. Equation (20) holds at $\alpha=0$ when $\pi \bar{y}_{2} \geq K$. When $\pi \bar{y}_{2}<K$, (20) holds, and $I$-control is feasible if and only if $\alpha \geq \alpha_{I}$, where (by A.2) $\alpha_{I} \in[0,1)$ is defined by:

$$
\alpha_{I} \equiv \max \left(0, \frac{K-\pi \bar{y}_{2}}{\pi \bar{y}_{1}+(1-\pi) \bar{y}_{2}}\right)
$$

E-control is instead ex ante feasible provided:

$$
\pi\left(\alpha \bar{y}_{1}+\bar{y}_{2}\right)+\frac{1-\pi}{2}\left[\alpha \bar{y}_{2}+L-(1-\alpha) \underline{y}_{2}\right] \geq K
$$

Inequality (21) holds at $\alpha=0$ provided $\pi \bar{y}_{2}+\frac{1-\pi}{2}\left(L-\underline{y}_{2}\right) \geq K$, otherwise $E$-control is feasible only when $\alpha \geq \alpha_{E}$ where $\alpha_{E} \in[0,1)$ is defined by:

$$
\alpha_{E} \equiv \max \left(0, \frac{K-\pi \bar{y}_{2}+\frac{1-\pi}{2}\left(L-\underline{y}_{2}\right)}{\pi \bar{y}_{1}+\frac{1-\pi}{2}\left(\bar{y}_{2}+\underline{y}_{2}\right)}\right) \text {. }
$$

These definitions imply that for $K \leq \pi \bar{y}_{2}$ we have $\alpha_{E}=\alpha_{I}=0$, for $K \in\left(\pi \bar{y}_{2}, \pi \bar{y}_{2}+\frac{1-\pi}{2}\left(L-\underline{y}_{2}\right)\right]$ we have $\alpha_{E}=0<\alpha_{I}$ (and $\alpha_{I}<L / \bar{y}_{2}$ by A.2), while for $K>\pi \bar{y}_{2}+\frac{1-\pi}{2}\left(L-\underline{y}_{2}\right.$ ) we have $0<\alpha_{I} \leq \alpha_{E}$. When $\alpha \geq \max \left(\alpha_{E}, \alpha_{I}\right)$ the first best is implemented under both $I$ - or $E$-control. If $\alpha_{E}<\alpha_{I}$, for $\alpha \in\left[\alpha_{E}, \alpha_{I}\right)$ the first best can only be implemented under E-control. If $\alpha_{E}>\alpha_{I}$, for $\alpha \in\left[\alpha_{I}, \alpha_{E}\right)$ the first best is only implemented under I-control.

For $\alpha<\min \left(\alpha_{E}, \alpha_{I}\right)$ the first best cannot be implemented. One possibility for parties is to restore break even by committing to liquidate the firm in $U$ and $B$. This outcome can be implemented under $I$-control by setting $h_{L}^{I}=L$ or by directly writing in the contract $\lambda(B)=$ $\lambda(U)=1$. Break-even is ensured provided:

$$
\pi\left(\alpha \bar{y}_{1}+\bar{y}_{2}\right)+(1-\pi) L \geq K
$$


which is fulfilled when $\alpha \geq \alpha_{D}$, where $\alpha_{D} \in[0,1)$ is defined by:

$$
\alpha_{D} \equiv \max \left(0, \frac{K-\pi \bar{y}_{2}-(1-\pi) L}{\pi \bar{y}_{1}}\right)
$$

Assumptions A.1 and A.2 imply that $\alpha_{D} \leq \min \left(\alpha_{I}, \alpha_{E}\right)$. Thus, for $\alpha \in\left[\alpha_{D}, \min \left(\alpha_{I}, \alpha_{E}\right)\right)$ liquidating the project in $B$ and $U$ ensures financing, at the cost though of over-liquidation.

For $\alpha \in\left[\alpha_{D}, \min \left(\alpha_{I}, \alpha_{E}\right)\right)$ parties reduce the frequency of such over-liquidation by using randomization devices. There are three possibilities, which we analyze below. First, the contract could set $E$-control with probability $x^{\widetilde{E}}$ and $I$-control with probability $1-x^{\widetilde{E}}$ and pledge all liquidation proceeds to $I$ by setting $h_{L}^{c}=L$ for $c=E, I$. Since by A.2 we have $\min \left(\alpha_{I}, \alpha_{E}\right)<L / \bar{y}_{2}$, this stochastic control contract implies that under E-control reorganization occurs for sure, while under I-control liquidation occurs for sure. In $\omega \in\{B, U\}$ this induces:

$$
\begin{array}{lc}
\text { repayment to } I: & (0.5)\left[x^{\widetilde{E}} \alpha\left(\bar{y}_{2}+\underline{y}_{2}\right)+\left(1-x^{\widetilde{E}}\right) L\right] \\
\text { ex post social welfare }: & (0.5)\left[x^{\widetilde{E}}\left(\bar{y}_{2}+\underline{y}_{2}\right)+\left(1-x^{\widetilde{E}}\right) L\right]
\end{array} .
$$

A second way to go is to set $E$-control with probability $x^{E}, I$-control with probability $1-x^{E}$ but induce only $E$ to implement ex post efficiency by setting $h_{L}^{E}=L-(1-\alpha) \underline{y}_{2}$ and $h_{L}^{I}=L$. This stochastic E-control contract induces an efficient reorganization decision with probability $x^{E}$ and deterministic liquidation with probability $1-x^{E}$. In $\omega \in\{B, U\}$ this induces:

$$
\begin{array}{lc}
\text { repayment to } I: & (0.5)\left\{x^{E}\left[\alpha \bar{y}_{2}+L-(1-\alpha) \underline{y}_{2}\right]+\left(1-x^{E}\right) L\right\} \\
\text { ex post social welfare }: & (0.5)\left[x^{E}\left(\bar{y}_{2}+L\right)+\left(1-x^{E}\right) L\right]
\end{array} .
$$

A third way to go is to set $I$-control with probability 1 and a stochastic under-collateralization so that with probability $\phi$ the investor receives $h_{L}^{I}=L-\alpha \bar{y}_{2}$ and with probability $(1-\phi)$ he receives $h_{L}^{I}=L$. This stochastic $I$-control contract induces an efficient decision with probability $\phi$ and deterministic liquidation with probability $1-\phi$. In $\omega \in\{B, U\}$ this induces:

$$
\begin{array}{cc}
\text { repayment to } I: & (0.5)\left[\phi 2 \alpha \bar{y}_{2}+(1-\phi) L\right] \\
\text { ex post social welfare }: & (0.5)\left[\phi\left(\bar{y}_{2}+L\right)+(1-\phi) L\right]
\end{array} \text {. }
$$

Holding the probability of non-contingent liquidation constant across the above three contracts, namely by setting $\phi=x^{E}=x^{\widetilde{E}}$, stochastic control is dominated by stochastic E-control and by 
stochastic I-control both in terms of ex post efficiency and ex ante repayment. As a result, stochastic control is never used. In general, and this is the statement of Lemma 4, stochastic E-control and stochastic I-control cannot be improved upon by any other random control allocation. This is because any random liquidation v. reorganization decision is akin to implementing a stochastic control contract with some probability. But the previous analysis then shows that this contract is dominated by implementing the same expected repayment by using a stochastic E-control or a stochastic I-control contract because for given repayment the latter ensure higher ex post efficiency than the random liquidation v. reorganization decision. This boosts ex post efficiency.

When comparing stochastic E-control with stochastic I-control, note that for a given probability $\phi=x^{E}$ of automatic liquidation, stochastic E-control guarantees a higher repayment than stochastic I-control if and only if $L-\alpha \bar{y}_{2}>(1-\alpha) \underline{y}_{2}$. Thus, when $\alpha \in\left(\alpha_{D}, \min \left(\alpha_{I}, \alpha_{E}\right)\right)$ stochastic E-control cannot be improved upon by any other contract when $L-\alpha \bar{y}_{2}>(1-\alpha) \underline{y}_{2}$, while stochastic I-control cannot be improved upon when $L-\alpha \bar{y}_{2} \leq(1-\alpha) \underline{y}_{2}$.

When parties use the stochastic I-control contract, they set the probability $\phi \leq 1$ at the minimum level insuring investor break-even:

$$
\pi\left(\alpha \bar{y}_{1}+\bar{y}_{2}\right)+\frac{1-\pi}{2}\left[\phi 2 \alpha \bar{y}_{2}+(1-\phi) L\right]=K
$$

When parties use the stochastic E-control contract they set the probability $x^{E} \geq 1$ at the maximum level consistent with investor break-even:

$$
\pi\left(\alpha \bar{y}_{1}+\bar{y}_{2}\right)+\frac{1-\pi}{2}\left\{x^{E}\left[\alpha \bar{y}_{2}+L-(1-\alpha) \underline{y}_{2}\right]+\left(1-x^{E}\right) L\right\}=K .
$$

As the break-even conditions (26) and (27) show, the probabilities of automatic liquidation, $(1-\phi)$ and $\left(1-x^{E}\right)$, are minimized for $\alpha=1$, increase as $\alpha$ decreases, and tend to 1 as $\alpha$ tends to $\alpha_{D}$.

Clearly, for $\alpha<\alpha_{D}$ not even full liquidation ensures break even and the firm is not financed.

Case 2: borrow $D>K$. We now show the (weak) suboptimality of setting $D=K+q$ for any $q>0$. To do so, we show that by setting $q>0$ rather than by under-collateralizing the investor's claim the parties cannot expand the parameter range in which the first best is implemented. We prove this proposition by assuming that $I$ has all bargaining power in renegotiation, which is the case most favourable for the working of a contract where $q>0$. Setting $q>0$ is akin to transforming the first period cash flow of the firm into $y_{1}(\omega)+q$. In state $G$, this simply implies 
that the maximum repayment that $I$ can extract becomes equal to:

$$
d_{1}(0)+d_{2}(1) \leq \alpha\left(\bar{y}_{1}+q\right)+\bar{y}_{2}
$$

Accounting for the higher first period cash flow, the above repayment is equivalent to the one previously obtained under no renegotiation. Indeed, since $I$ is assumed to have all the bargaining power he is able to extract from $E$ the latter's future control rent $(1-\alpha) \bar{y}_{2}$. Below we consider the general case where the bargaining power of the investor can be anything.

When $\omega \in\{U, B\}$ the contract can specify an initial payment $\alpha q$ at $t=1$ and a financial distress state becomes similar to $G$. Suppose first that $q>\bar{y}_{2}$. In this case, in order to guarantee reorganization in $U$, the entrepreneur is willing to bribe $I$ up to $(1-\alpha) \bar{y}_{2}$ at $t=1$, which is feasible because $q>\bar{y}_{2}$. As a result, ex post efficiency is attained and the investor obtains a total payment of $\alpha q+\bar{y}_{2}$ in $U$ and $\alpha q+L$ in $B$ (in state $B, E$ prefers to default at $t=1$ ). Ex post efficiency is attained and investor break even is fulfilled provided:

$$
\pi\left[\alpha \bar{y}_{1}+\bar{y}_{2}-q(1-\alpha)\right]+\frac{1-\pi}{2}\left\{\left[\bar{y}_{2}-q(1-\alpha)\right]+[L-q(1-\alpha)]\right\} \geq K
$$

It is easy to see that given $q>\bar{y}_{2}$, the above condition is harder to fulfill than condition (20) prevailing under $I$-control. As a result, $q>\bar{y}_{2}$ cannot improve upon $I$-control. The general intuition here is that even though setting $q>0$ yields an ex post efficient outcome, $E$ keeps $(1-\alpha) q$ for himself in states $G$ and $B$, which reduces ex ante break even.

Suppose now that $q<\bar{y}_{2}$. In this case, the maximum payment that can be extracted from $E$ in state $U$ over and above $\alpha q$ is equal to $(1-\alpha) q$ in $U$; this guarantees reorganization if an only if $(1-\alpha) q+\alpha \bar{y}_{2}>L$. In state $B$ instead $I$ can only extract $\alpha q+L$ in $B$. If ex post efficiency is attained, investor break even is fulfilled provided:

$$
\pi\left[\alpha \bar{y}_{1}+\bar{y}_{2}-q(1-\alpha)\right]+\frac{1-\pi}{2}\left\{\alpha \bar{y}_{2}+[L-q(1-\alpha)]\right\} \geq K
$$

which is stricter than the condition (21) guaranteeing the feasibility of E-control when $q>\underline{y}_{2}$. As a result, setting $q>0$ cannot improve upon the E-control and $I$-control contracts.

Lack of commitment and ex post renegotiation. We now relax the assumptions of commitment and no ex post renegotiation. These assumptions are not central in our analysis because they only affect investor repayment in $G$, not the resolution of financial distress. This is 
because in states $U$ and $B$ it is always incentive compatible for the party in control to take the efficient reorganization decision (so that lack of commitment is not an issue and renegotiation does not occur) or, when the allocation is not ex post efficient, $E$ has not enough resources to bribe $I$. Lack of commitment in $G$ can only arise when $d_{2}(0)>L$. Thus, for the liquidation policy $\lambda(0)=1$ to be credible it must be that $d_{2}(0) \leq L$. For $\alpha \bar{y}_{2} \leq L$ this condition is automatically fulfilled and nothing changes. For $\alpha \bar{y}_{2}>L$ the contract sets $d_{2}(0)=L$. In this case, it is easy to see from the proof of Lemma 1 that the repayment limit is again $d_{2}(1)+d_{2}(1) \leq \alpha \bar{y}_{1}+\bar{y}_{2}$, so nothing changes in terms of equilibrium repayment.

Renegotiation can undermine the liquidation policy $\lambda(0)=1$ because liquidation in $G$ is not ex post efficient. Suppose that the bargaining power of $E$ is equal to $e \in[0,1]$. After defaulting (i.e. after paying only $\alpha \bar{y}_{1}$ to $\left.I\right), E$ approaches $I$ and promises him a share $(1-e)$ of the renegotiation surplus $\left(\bar{y}_{2}-L\right)$. We assume, w.l.o.g. $d_{2}(0)=0$. Bribing $I$ is always feasible for $E$, as the latter can pledge up to $\alpha \bar{y}_{2}$ future revenues and additionally pay $(1-\alpha) \bar{y}_{2}$ from his $t=1$ cash flow. This is sufficient for bribing $I$ into efficient reorganization at any value of the bargaining power because $\bar{y}_{2}>L+(1-e)\left(\bar{y}_{2}-L\right)$. In this case, the investor in $G$ obtains at most $\alpha \bar{y}_{1}+e L+(1-e) \bar{y}_{2}$. As a result, renegotiation reduces what $E$ can commit to repay in $G$. This only reduces the value of thresholds $\alpha_{E}, \alpha_{I}$, and $\alpha_{S}$ but all of our main results are unaffected.

Proof of Lemma 5 and of Proposition 2. We begin with the proof of Lemma 5 . If $E$ borrows from $N>1$ creditors under $I$-control contracts giving each creditor a share $1 / N$ of reorganization proceeds and an amount $\min \left(\alpha \bar{y}_{2}, L\right) / N$ of liquidation proceeds, ex post efficiency is attained in line with Proposition 1. As in the one creditor case, the liquidation policy in $G$ implements premature liquidation if and only if $E$ defaults on any number of creditors while it implements efficient continuation if $E$ repays in full. The resulting repayment in $G$ can be arbitrarily split among all creditors. For any $N>1$, this yields the first best for $\alpha \geq \alpha_{I}$.

Proposition 2 immediately follows from the fact that the aggregate amount of under-collateralization $S^{I}=\left[L-\max \left(L-\alpha \bar{y}_{2}, 0\right)\right]$ can be distributed to the creditor without control rights (as opposed to $E)$. Thus, under full ex post efficiency creditors as a whole can be pledged up to $\left(\alpha \bar{y}_{2}+L\right) / 2$. Since total repayment in state $G$ does not change, the first best outcome is attainable, provided $\alpha \geq \widehat{\alpha}_{I} \geq \alpha_{I}$.

Proof of Corollary 1. For $\alpha<\alpha_{D}$, the firm is not financed. To see what happens for $\alpha \geq \alpha_{D}$, consider a debt structure consisting of one creditor holding control rights, $|C|=1$, and a number $|\bar{C}|$ of creditors without control, for a total number of $N=1+|\bar{C}|$ creditors. The controlling 
creditor is pledged all reorganization proceeds and an amount $\alpha \bar{y}_{2}$ of liquidation proceeds. This creditor redistributes an aggregate amount $S=L-\alpha \bar{y}_{2}$ of liquidation proceeds to the remaining $|\bar{C}|$ creditors. By setting $|\bar{C}|=+\infty$, consolidation of claims does not occur. Given the definition of

$\widehat{\alpha}_{I}$, for $\alpha \geq \widehat{\alpha}_{I}$ this debt structure attains the first best. If $\alpha_{D} \leq \alpha \leq \widehat{\alpha}_{I}$, the above arrangement is infeasible, and $E$ must commit to sometimes liquidating the firm in $U$. By the proof of Proposition 1 , this is attained by giving the creditor in control a stochastic $I$-control contract where $\phi$ is determined according to (19). Once more, $|\bar{C}|=+\infty$ prevents consolidation from occurring when the creditor in control efficiently reorganizes.

\section{Appendix 2: Extensions}

A2.1: Uncertain Cash Flows and Liquidation Values. We now show that floating charges are also optimal if first period cash flows $y_{1}$, liquidation values $L$, and reorganization values $y_{2}$ are stochastic, taking on a continuum of values. To simplify the exposition, we later impose also a mild restriction on the distribution of $\left(y_{1}, y_{2}, L\right)$.

As a benchmark, consider the optimal contract when courts perfectly verify $\left(y_{1}, y_{2}, L\right)$ but managers can still seize a fraction $(1-\alpha)$ of profits. The optimal contract sets state-contingent payments $d_{1}\left(y_{1}, y_{2}, L\right)$ at $t=1, d_{2}\left(y_{1}, y_{2}, L\right)$ at $t=2$ and liquidation policy $\lambda\left(y_{1}, y_{2}, L\right)$. If $E$ repays less than $d_{1}\left(y_{1}, y_{2}, L\right)$ at $t=1$, the court fires the manager and implements $\lambda\left(y_{1}, y_{2}, L\right)$, so that under continuation $\left[\lambda\left(y_{1}, y_{2}, L\right)=0\right]$ a new management team yielding $y_{2}$ is hired. To avoid being fired, at $t=1$ the manager is willing to pay the continuation rent $(1-\alpha) y_{2}$, implying that if $t=1$ and cash flows are so high that $y_{1}>y_{2}$, over the two periods the creditor obtains a total repayment of $\left(\alpha y_{1}+y_{2}\right)$ if $\lambda\left(y_{1}, y_{2}, L\right)=0$, and $\left(\alpha y_{1}+L\right)$ otherwise. It is evident that if $y_{1}>y_{2}$ there is no trade-off between ex ante and ex post efficiency so that the optimal contract sets $\lambda\left(y_{1}, y_{2}, L\right)=0$ if and only if $y_{2}>L$ and there is no cost of creditor control.

To simplify matters, we focus precisely on this case by assuming that if the firm is performing relatively well in the first period, namely $y_{1}>y_{2}$, then reorganization is socially efficient, namely $y_{2}>L$. This implies that all states where $y_{1}>y_{2}$ are then analogous to state $G$ in the three-states model in the main body of the paper. As a result, $\lambda\left(y_{1}, y_{2}, L\right)$ is mechanically set to be equal to zero for $y_{1}>y_{2}$. When instead $y_{1}<y_{2}$ the debtor cannot pay at $t=1$ all of his reorganization rent and he can pay at most a bribe to $I$ equal to $(1-\alpha) y_{1}$, implying that a tradeoff between ex post and ex ante efficiency arises. Denote by $I I=I I\left(y_{1} \leq y_{2}\right)$ an indicator function taking value one when $y_{1} \leq y_{2}$ and zero otherwise. The optimal liquidation policy for states in which $y_{1} \leq y_{2}$, 
again assuming that $y_{1}, y_{2}, L$ are all verifiable in court, then solves:

$$
\begin{aligned}
& \max _{\lambda\left(y_{1}, y_{2}, L\right) \text { for } y_{1}<y_{2}} \mathbb{E}\left[y_{1}+y_{2}+\lambda\left(y_{1}, y_{2}, L\right)\left(L-y_{2}\right) I I\right] \\
& \text { s.t. } \mathbb{E}\left\{\left(\alpha y_{1}+y_{2}\right)(1-I I)+\left(\alpha y_{2}+y_{1}\right) I I+\lambda\left(y_{1}, y_{2}, L\right)\left[L-\alpha y_{2}-(1-\alpha) y_{1}\right] I I\right\} \geq K
\end{aligned}
$$

First order conditions with respect to $\lambda\left(y_{1}, y_{2}, L\right)$ imply that the optimal contract liquidates the firm in states in which $y_{1}<y_{2}$ if and only if:

$$
\left(L-y_{2}\right)+\nu\left[L-\alpha y_{2}-(1-\alpha) y_{1}\right]>0
$$

where $\nu$ is the multiplier attached to I's break even constraint. If $\nu=0$, liquidation occurs iff $L>y_{2}$. If instead $I$ 's break even constraint is binding then liquidation occurs if $L>L^{*}\left(y_{2}, y_{1}\right) \equiv$ $\left\{y_{2}+\nu\left[\alpha y_{2}+(1-\alpha) y_{1}\right]\right\} /(1+\nu)$, so that ex post inefficient liquidation is implemented whenever $y_{2}>L>L^{*}\left(y_{2}, y_{1}\right)$. Crucially, inefficient ex post reorganization never occurs because $y_{2}$ can never be lower than $L^{*}\left(y_{2}, y_{1}\right)$. Threshold $L^{*}\left(y_{2}, y_{1}\right)$ is a linear combination of $y_{2}$ and $y_{1}$, which we express as $L^{*}\left(y_{2}, y_{1}\right)=v y_{2}+(1-v) y_{1}$, where $v \in[0,1]$.

We now show that in financial distress (i.e. if $y_{1}<y_{2}$ ) a debt structure sharing the same features of the one described in Proposition 2 can implement for every $\left(y_{2}, y_{1}, L\right)$ the constrained optimal outcome in which liquidation occurs iff $y_{1}<y_{2}$ and $L>L^{*}\left(y_{2}, y_{1}\right)$, even if courts cannot verify $y_{2}$ and total repayment to creditors is the same. As in Section 2, we continue to assume that at $t=1$ courts determine both $y_{1}$ and $L$.

Suppose then that under the original debt contract one creditor is given control over the reorganization v. liquidation decision upon financial distress and he is also given the right to replace the existing manager with a new manager. This creditor is then entitled to a fixed share $g$ of first period repayment (both in the case of full repayment and in the case of default) and a fixed share $l$ of liquidation proceeds. Additionally, suppose that such creditor is also promised a fixed share $x$ of reorganization proceeds. The remaining repayments are promised to the creditor class without control rights. The contract also forbids $E$ from discriminating in default among different creditors (if he does so, the firm is automatically liquidated). Consider now the outcome implemented by this debt structure.

When $y_{1}<y_{2}, E$ cannot pay his reorganization rent $(1-\alpha) y_{2}$ but only $(1-\alpha) y_{1}$ (for a total 
repayment of $y_{1}$ at $t=1$ ), so that the creditor exerts control and liquidates if and only if:

$$
x \alpha y_{2}+g y_{1}<g \alpha y_{1}+l L
$$

where the left hand side captures the amount of first and second period repayment under reorganization accruing to the creditor in control, while the right hand side captures the latter creditor's repayment under liquidation (which is a portion of total repayments $\alpha y_{1}$ at $t=1$ and $l$ at $t=2$ ). Condition (29) can be rewritten as:

$$
L>(x / l) \alpha y_{2}+(g / l)(1-\alpha) y_{1} \cdot
$$

It is then immediate to see that, the optimal reorganization policy is implemented by giving the creditor in control all reorganization proceeds, (i.e. $x=1$ ) and by setting $g$ and $l$ such that:

$$
l=\frac{\alpha}{v}<1, g=\frac{1-v}{v} \frac{\alpha}{1-\alpha}<1
$$

Crucially, the values of $l$ and $g$ in conditions (31) make condition (30) equivalent to condition $L>L^{*}\left(y_{2}, y_{1}\right)$, implying that creditor control implements the constrained optimal reorganization policy in financial distress. Obviously, the remaining share of proceeds $1-l$ and $1-g$ are distributed to the second class of creditors, so that the same level of welfare as in problem (28) is attained.

When $y_{1}>y_{2}$ the debtor can pay his reorganization rent $(1-\alpha) y_{2}$ to the creditor (otherwise the creditor replaces him with a new management team). Under the original contract, the creditor reorganizes if and only if:

$$
\alpha y_{2}+g\left[\alpha y_{1}+(1-\alpha) y_{2}\right]>g \alpha y_{1}+l L
$$

Condition (29) can be rewritten as:

$$
[\alpha+g(1-\alpha)] y_{2}>l L
$$

It is easy to check that at the optimal contract in (31) condition (33) is always met because $y_{2}>L$. As a result, the creditor in control always efficiently reorganizes for $y_{1}>y_{2}$ and maximal repayment is extracted from $E$ due to the threat of replacement.

The general idea, then, is that by making the creditor in control claimant to reorganization 
proceeds (and by under-collateralizing his claim in financial distress, as reflected by $l<1$ ) allows to make him internalize the social benefits of efficient reorganization, removing any liquidation bias on his part. Crucially, note that even in this general setting the extent of under-collateralization of the controlling creditor increases as $\alpha$ becomes lower. Indeed, if $\alpha=1$, then $v=1$ and $l=1$ as well, suggesting that the under-collateralization of the creditor in control is a general feature of optimal debt structures when liquidation proceeds are easier to pledge than cash flows. More broadly, the extent of reorganization in the constrained optimum falls as $\alpha$ falls [as reflected by the fact that $v$ and thus $L^{*}\left(y_{2}, y_{1}\right)$ fall as $\alpha$ falls], precisely capturing the idea that at low investor protection it is ex ante optimal to have inefficient liquidation. 


\section{References}

Aghion, Philippe, and Patrick Bolton, 1992, An incomplete contracts approach to financial contracting, Review of Economic Studies 59, 473-494.

Aghion, Philippe, Oliver Hart, and John Moore, 1992, The economics of bankruptcy reform, Journal of Law, Economics and Organization 8, 523-546.

Ayotte, Kenneth M., and Hayong Yun, 2009, Matching bankruptcy laws to legal environments, Journal of Law, Economics, and Organization 25, 2-30.

Baird, Douglas G., 1986, The uneasy case for corporate reorganizations, Journal of Legal Studies $15,127-147$.

Bebchuk, Lucien Arye, 1988, A new approach to corporate reorganizations, Harvard Law Review 101, $775-804$.

Bergman, Nittai K., and Daniel Nikolaievski, 2007, Investor protection and the Coasian view, Journal of Financial Economics 84, 738-771.

Berglöf, Erik, Gérard Roland, and Ernst-Ludwig von Thadden, 2010, Optimal debt design and the role of bankruptcy, Review of Financial Studies 23, 2648-2679.

Berglöf, Erik, and Ernst-Ludwig von Thadden, 1994, Short-term versus long-term interests: Capital structure with multiple investors, Quarterly Journal of Economics 109, 1055-1084.

Berkovitch, Elazar, and Ronen Israel, 1999, Optimal bankruptcy laws across different economic systems, Review of Financial Studies 12, 347-377.

Biais, Bruno, and Thomas Mariotti, 2008, Credit, wages and bankruptcy laws, Journal of the European Economic Association 7, 939-973.

Bisin, Alberto, and Adriano A. Rampini, 2006, Exclusive contracts and the institution of bankruptcy, Economic Theory 27, 277-304.

Bolton, Patrick, and Howard Rosenthal, 2002, Political intervention in debt contracts, Journal of Political Economy 110, 1103-1134.

Bolton, Patrick, and David S. Scharfstein, 1996, Optimal debt structure and the number of creditors, Journal of Political Economy 104, 1-25. 
Bris, Arturo, and Ivo Welch, 2005, The optimal concentration of creditors, Journal of Finance 60, 2193-2212.

Brunner, Antje, and Jan Pieter Krahnen, 2008, Multiple lenders and corporate distress: Evidence on debt restructuring, Review of Economics Studies 75, 415-442.

Davies, Paul, 1997, Gower's principles of modern company law, London, Sweet and Maxwell.

Dewatripont, Mathias, and Jean Tirole, 1994, A theory of debt and equity: Diversity of securities and manager-shareholder congruence, Quarterly Journal of Economics 109, 1027-1054.

Diamond, Douglas W., 2004, Committing to commit: Short-term debt when enforcement is costly, Journal of Finance 59, 1447-1480.

Diamond, Douglas W., 1993, Seniority and maturity of debt contracts, Journal of Financial Economics 33, 341-368.

Diamond, Douglas W., 1991, Monitoring and reputation: The choice between bank loans and directly placed debt, Journal of Political Economy 99, 689-721.

Diamond, Douglas W., 1984, Financial intermediation and delegated monitoring, Review of Economic Studies 51, 393-414.

Djankov, Simeon, Oliver D. Hart, Caralee McLiesh, and Andrei Shleifer, 2008a, Debt enforcement around the world, Journal of Political Economy 116, 1105-1149.

Djankov, Simeon, Rafael La Porta, Florencio Lopez-de-Silanes, and Andrei Shleifer, 2008b, The law and economics of self-dealing, Journal of Financial Economics 88, 430-465.

Franks, Julian, R., and Gyöngyi Lóránth 2006, A study of inefficient going concerns in bankruptcy, Mimeo, London Business School.

Franks, Julian R., and Kjell G. Nyborg, 1996, Control rights, debt structure and the loss of private benefits: The case of the UK Insolvency Code, Review of Financial Studies 9, 1165-1210.

Franks, Julian R., Kjell G. Nyborg and Walter N. Torous, 1996, A comparison of U.S., U.K. and German insolvency codes, Financial Management 25, 19-30.

Franks, Julian, R., and Oren Sussman, 2005a, Financial distress and bank restructuring of small 
to medium size U.K. companies, Review of Finance 9, 65-96.

Franks, Julian, R., and Oren Sussman, 2005b. Financial innovations and corporate insolvency. Journal of Financial Intermediation 14, 283-317.

Franks, Julian R., and Walter N. Torous, 1994, A comparison of financial recontracting in distressed exchanges and Chapter 11 reorganizations, Journal of Financial Economics 35, 349-370.

Gennaioli, Nicola, 2011, Optimal contracts with enforcement risk, forthcoming, Journal of the European Economic Association.

Gennaioli, Nicola, and Stefano Rossi, 2010, Judicial discretion in corporate bankruptcy, Review of Financial Studies 23, 4078-4114.

Gertner, Robert, and David S. Scharfstein, 1991, A theory of workouts and the effects of reorganization law, Journal of Finance 46, 1189-1222.

Hart, Oliver, 1995. Firms, contracts and financial structure. Oxford: Clarendon Press.

Hart, Oliver, and John Moore, 1998, Default and renegotiation: A dynamic model of debt, Quarterly Journal of Economics 114, 1-41.

Jackson, Thomas H., 1986, The logic and limits to bankruptcy, Boston: Little, Brown and Company. Jensen, Michael C., 1989, Active investors, LBOs and privatization of bankruptcy, Journal of Applied Corporate Finance 2, 35-44.

Jensen, Michael C., and William H. Meckling, 1976, Theory of the firm: Managerial behavior, agency costs and ownership structure, Journal of Financial Economics 3, 305-360.

Kahl, Matthias, 2002, Economic distress, financial distress, and dynamic liquidation, Journal of Finance 57, 135-168.

Lambert-Mogilianski, Ariane, Constantin Sonin, and Ekaterina Zhuravskaya, 2007, Are Russian commercial courts biased? Evidence from a bankruptcy law transplant, Journal of Comparative Economics 35, 254-77.

La Porta, Rafael, Florencio Lopez-de-Silanes, and Andrei Shleifer, 2008, The economic consequences of legal origins, Journal of Economic Literature 46, 285-332. 
La Porta, Rafael, Florencio Lopez-de-Silanes, Andrei Shleifer, and Robert W. Vishny, 1998, Law and finance, Journal of Political Economy 101, 678-709.

Lerner, Josh, and Antoinette Schoar, 2005, Does legal enforcement affect financial transactions? The contractual channel in private equity, Quarterly Journal of Economics 120, 223-246.

Manove, Michael, A. Jorge Padilla, and Marco Pagano, 2001, Collateral versus project screening: A model of lazy banks, RAND Journal of Economics 32, 727-744.

Maskin, Eric S., 1999, Nash equilibrium and welfare optimality, Review of Economic Studies 66, $23-38$.

Myers, Stewart C., 1977, Determinants of corporate borrowing, Journal of Financial Economics 5, $147-175$.

Park, Cheol, 2000, Monitoring and structure of debt contracts, Journal of Finance 55, 2157-2195.

Povel, Paul, 1999, Optimal "soft" or "tough" bankruptcy procedures, Journal of Law, Economics and Organization 15, 659-684.

Qian, Jun and Philip E. Strahan, 2007, How law and institutions shape financial contracts: the case of bank loans, Journal of Finance 62, 2803-2834.

Rajan, Raghuram G., 1992, Insiders and outsiders: The choice between informed and arm's length debt, Journal of Finance 47, 1367-1400.

Shleifer, Andrei, and Daniel Wolfenzon, 2002, Investor protection and equity markets, Journal of Financial Economics 66, 3-27.

Winton, Andrew, 1995, Costly state verification and multiple investors: the role of seniority, Review of Financial Studies 8, 91-123. 